\title{
Advanced Analytical Study of Process Streams for a Rational Optimization of Hydrothermal Gasification
}

\author{
David Baudouin,* Daniil Salionov, Frédéric Vogel, and Saša Bjelić \\ Cite This: ACS Eng. Au 2021, 1, 134-147 \\ Read Online
}

ABSTRACT: Hydrothermal processes are promising technologies for an efficient valorization of wet biomass feedstocks or wastes. Their performance strongly depends on the composition of the feedstock, and methods to analyze such complex mixtures along with the produced effluents are in constant progress. Herein, catalytic hydrothermal gasification (cHTG) was used to valorize process water produced from the hydrothermal liquefaction of pine wood. A detailed analysis of the effluents and streams at various points of the process was performed. About 54\% of the feed's chemical energy could be transferred to synthetic natural gas while an excellent extraction of minerals (98\%) into a concentrated brine (27 wt \% dry matter) could be achieved. The low gasification efficiency observed and the origin of the $41 \%$ and $44 \%$ loss of chemical energy and carbon

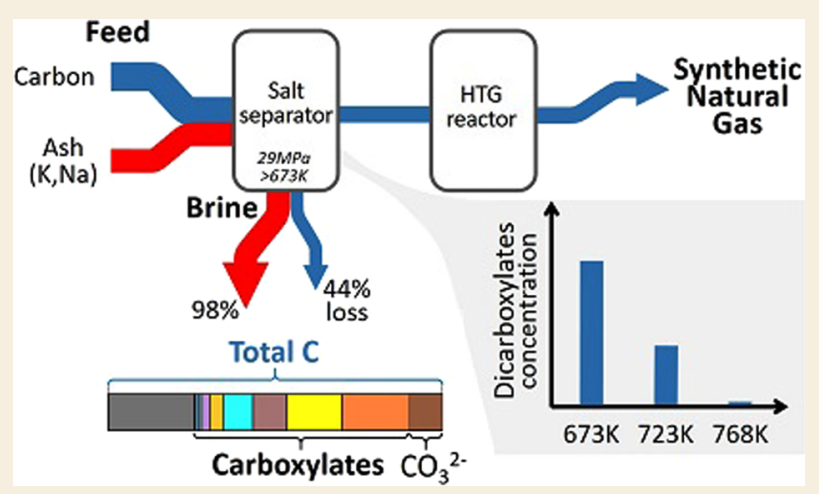
in the brine, respectively, were investigated by high-pressure liquid chromatography-high-resolution mass spectrometry (HPLCHRMS) analysis of the feed and the effluents from the salt separator. This allowed for identifying mono- and polycarboxylates accounting for $71 \%$ of the carbon in the brine. Increasing temperature in the salt separator to favor decarboxylation reaction was identified as pivotal to improve synthetic natural gas yields, with a 20 -fold decrease of carboxylate concentration being reached with a temperature rise from 723 to $768 \mathrm{~K}$. The use of two new approaches to estimate the high heating value (HHV) of this feed rich in volatile organic compounds is also reported.

KEYWORDS: hydrothermal processing, biomass gasification, supercritical water, waste treatment, nutrient recovery, salt separation, high-resolution mass spectrometry, higher heating value, chemical oxygen demand, deoxygenation

\section{INTRODUCTION}

With a rising concern for energy security and mitigation of climate change, the development of renewable liquid transportation fuels is crucial for certain transport sectors such as aviation, sea, or heavy-duty road transport. Compared to production pathways based on other conversion technologies, it was found that fuels derived from the hydrothermal liquefaction (HTL) of lignocellulosic biomass have the lowest minimum selling price, down to $0.7 \mathrm{EUR} \cdot \mathrm{L}^{-1}$, for the jet fuel products. ${ }^{1}$ In the HyFlexFuel project, hydrothermal liquefaction is used to produce biocrude from a large variety of biomass and wastes, ${ }^{2,3}$ biocrude that is further upgraded and refined into drop-in fuels using existing infrastructure. ${ }^{4}$ HTL produces a large amount of process water, which is a waste stream that needs to be treated. This process water contains, aside from a large variety of inorganic components, considerable amounts of water-soluble organic compounds that may be toxic, such as phenolic compounds, and that can be problematic to existing valorization processes such as anaerobic digestion. One route studied to valorize this aqueous effluent is to integrate a catalytic hydrothermal gasification (cHTG) unit in order to convert this waste into synthetic natural gas (SNG), a clean organic-free process water, and a brine concentrating most inorganic compounds and nutrients. Downstream of the cHTG process, the nutrients in the brine, such as phosphorus, are further valorized, e.g., into struvite. ${ }^{5}$ Recently, the U.S. Department of Energy's (DOE) Pacific Northwest National Laboratory (PNNL) and Genifuel have announced the launch of a pilot plant following the same concept as the HyFlexFuel project using wet organic waste from a wastewater treatment plant in Martinez, California. ${ }^{6}$

In the cHTG process, supercritical water gasification is performed at low temperature $(653-723 \mathrm{~K})$ to increase selectivity toward methane, which is thermodynamically favored over hydrogen at these conditions. To ensure the reaction is fast enough for a scalable continuous process, a catalyst is used to gasify in supercritical water organics into synthetic natural gas,

Received: June 7, 2021

Published: September 8, 2021 
mainly composed of $\mathrm{CO}_{2}, \mathrm{CH}_{4}$, and $\mathrm{H}_{2}$. Note that in addition to the temperature, the composition of the gas strongly depends on the concentration and composition of the organics in the feed, with a higher concentration of carbon favoring selectivity toward methane. In order to protect the catalyst from fouling, salts are separated upstream the catalyst, exploiting their low solubility in supercritical water. ${ }^{2,8-12}$ At the Paul Scherrer Institute (PSI), a salt separator is used to continuously extract salts from a wet biomass stream at pressures of 25-29 MPa and temperatures of $693-773 \mathrm{~K}$, with extraction efficiencies of up to $99 \% .{ }^{11-13}$ In supercritical water, salts are separated into two main families on the basis of their phase behavior. Salts that precipitate are categorized as type 2 and those forming a liquid-like brine as type $1 .{ }^{14}$ Unfortunately, the phase behavior of a mixture of salts cannot be predicted accurately, as for instance mixtures of two type 2 salts might behave as type $1 .{ }^{14-16}$ In parallel, organic salts such as carboxylates can theoretically also be separated from the main stream in the salt separator, and thus, the continuous salt extraction efficiency would depend both on the inorganic and organic composition of the feed.

The best-performing catalyst for hydrothermal gasification known to date is ruthenium supported on activated carbon $(\mathrm{Ru} /$ AC). Ru offers high gasification rates and excellent selectivity to methane, allowing to reach thermodynamic equilibrium and good stability toward sintering ${ }^{7,17,18}$ and leaching, ${ }^{19}$ while AC is one of the rare catalyst supports that is stable in supercritical water (SCW) and offers both high surface area and low cost. ${ }^{7}$ If a proper space velocity is used, all liquefied organic matter dissolved in supercritical water will be gasified to a thermodynamically equilibrated synthetic natural gas by such a catalyst. Ultimately, the percentage of carbon ending up in the SNG depends on the carbon loss in the brine effluent extracted from the salt separator. This carbon loss can come from the presence of carbonates, ionic/charged organics or carbon rich solids, e.g. coke. However, little is known about the phase behavior of ionic/charged organics in SCW and their separation efficiency, among others because of their relatively low stability under hydrothermal conditions.

In previous studies on the hydrothermal gasification of biomass using a salt separator, little attention was given to the chemical composition of the separator effluents. ${ }^{20,21}$ The loss of carbon in the brine leaving the salt separator can vary from 6 to up to $40 \%-60 \%{ }^{20,21}$ and will likely depend on the percentage of total inorganic carbon (TIC) or on the quantity and size of organic particles in the feed. Many parameters, often intercorrelated, impact carbon loss in the brine. A better understanding of the chemical composition of the feed and of the two effluents of the salt separator would contribute toward understanding the correlation between gasification efficiency, feed chemical composition, and process parameters and would support a rational selection of optimal process conditions.

The evaluation of the chemical composition of the products from hydrothermal conversion, and in particular HTL aqueous phase, is a challenging task first because of the extreme complexity of the mixture and second due to the high share of nonvolatile compounds. ${ }^{22,23}$ Many studies have been performed with the aim to better understand the chemical composition of this effluent with the use of conventional methods such as gas chromatography coupled to mass spectrometry. ${ }^{24-26}$ The identification of small organic acids, alcohols, ketones, and phenolic compounds was reported; however, those species correspond only to ca. $30 \mathrm{wt} \%$ of the organics present in the HTL-aqueous phase at a temperature of $280{ }^{\circ} \mathrm{C}$, which is the typical gas chromatography (GC) injection condition. ${ }^{23}$ More advanced analytical techniques should be used to study the global composition of the aqueous phase. High-pressure liquid chromatography (HPLC) coupled to high-resolution mass spectrometry (HRMS) with soft ionization methods such as electrospray is a promising way to evaluate the composition of hydrothermal process products. ${ }^{27}$ By precisely measuring the ion mass and its isotopic distribution, the chemical formula of a compound can be determined. The chromatographic separation, in addition, decreases the impact of the matrix effect derived from the chemical complexity of the sample and allows to separate isomeric species.

In this paper, we first present the overall performance of the cHTG valorization of HTL-process water produced from pine wood sawdust, report effluent composition, and draw ash, carbon, and other elemental mass balances at every step of the process. Problems met in the measurement of the higher heating value (HHV) for HTL-process water containing high levels of volatile organic compounds are discussed and two solutions are presented, allowing to draw more accurate chemical energy balances. A detailed study of the chemical composition of the feed and the two effluents of the salt separator was also performed using HPLC-HRMS to better understand the high loss of carbon and chemical energy in the brine stream. A quantification method based on ionization efficiency was used to quantify detected carboxylates. This comprehensive study triggered an approach to improve the SNG yield with this category of feedstock that was validated by batch reactor tests.

\section{MATERIAL AND METHODS}

\section{Chemicals}

Methanol $(\mathrm{MeOH})$ and water, both HPLC-MS grade, were purchased from Avantor VWR International. Formic acid and diethyl ether, both HPLC grade, were purchased from Merck. Succinic, glutaric, adipic, pimelic, subaric, azelaic, sebacic, phthalic, mandelic, tricarballylic, and glycolic acids, all $>99 \%$ purity, were purchased from Merck. Lactic acid (>99\%) was purchased from Fluorochem.

\section{HTL-Process Water from Pine Tree Used As Feed for cHTG} Tests

The feed used in the hydrothermal gasification test described in this work is a process water collected from the hydrothermal liquefaction of pine wood sawdust using $\mathrm{KOH}$ as a catalyst. This process water was produced using the continuous HTL pilot plant at Aarhus University described in ref 2 .

In order to increase the thermal efficiency of cHTG, organics in the HTL process water were concentrated. With that objective, the HTL process water was recycled five times by using the process water produced in one HTL run to disperse pine wood sawdust used in the following run. This was done to increase the organic carbon fraction in that waste stream from HTL and thus increase the thermal efficiency of cHTG. Note that fresh water was also added to the saw dust as not enough process water was produced at the end of each HTL run to reach the optimal dry matter concentration. The obtained process water with a total organic carbon concentration (TOC) of $34 \mathrm{~g} \cdot \mathrm{L}^{-1}$ was used as a feed for the catalytic hydrothermal gasification tests performed at PSI.

\section{Continuous Catalytic Hydrothermal Gasification Unit}

The catalytic gasification unit used for this work is described in detail in ref 20. In summary, the demonstration unit used in this study, named KONTI-C and located on PSI's Energy System Integration (ESI) platform, consists of four sections: a pumping section, a salt separation section, a catalytic gasification section, and a pressure control/phase separation section (see simplified scheme in Figure 3). The pumping capacity is approximately $1 \mathrm{~kg} \cdot \mathrm{h}^{-1}$ for a pressure of $25-30 \mathrm{MPa}$. 
The salt separator $(0.56 \mathrm{~L}$ inner volume) consists of a cylindrical vessel with a bottom inlet (injection at ca. one third of the vessel height through an injection pipe). The vessel was heated by six independent sets of heaters, allowing a vertical gradient of temperature typically ranging from ca. 623 to $743 \mathrm{~K}$, resulting in the liquefaction and partial gasification of the feed. Under these supercritical water conditions, salt solubility decreases drastically, resulting in the formation of a salt-rich phase, a solid (salt precipitation), and/or a fluid rich in dissolved salts (brine). The salt separator consists of two outlets. The first one is located at its bottom and allowed for the extraction of the salt-rich brine. The flow of this effluent was controlled by a liquid mass flow controller, and an analytical balance was used to measure the mass flow rate. The other outlet delivered an effluent depleted in minerals but rich in organic compounds located at the top of the salt separator and was connected to the gasification reactor. This vessel is filled with a first fixed bed consisting of a $\mathrm{ZnO}$-based sulfur trap (482 g, Katalco 32-5, Johnson Matthey) protecting a second fixed bed of a 5 wt \% Ru/AC catalyst gasification catalyst ( $484 \mathrm{~g}, \mathrm{BASF}$ ).

After gasification, the effluent was cooled and depressurized to atmospheric pressure and the aqueous phase was separated from the gaseous phase. The flow of synthetic natural gas was dehumidified at ca. $278 \mathrm{~K}$, measured by a gas meter, and its composition was determined by a calibrated micro GC (3000 Micro GC, INFICON). As for the liquid phase, referred to as process water, it was collected in a container located on an analytical balance to measure its mass flow rate.

Samples were taken over ca. $1 \mathrm{~h}$ long time segments during steadystate operation and merged together after the run if the process conditions remained constant (within $2 \%$ from the mean values).

\section{Batch Reactor}

The gasification experiments were conducted in a 316 stainless steel reactor ( $\mathrm{HiP}$ ) with an inner volume of $28 \mathrm{~mL}$ using the same feed as for the continuous test but after being stored several months in a fridge (aging expected). ${ }^{28}$ The batch experiments were performed at 673,733 , and $783 \mathrm{~K}$ while maintaining the pressure at $28.5 \pm 3 \mathrm{MPa}$. For a pressure of $29 \mathrm{MPa}$, water densities of 219,131 , and $105 \mathrm{~kg} \cdot \mathrm{m}^{-3}$ were estimated at these three temperatures, respectively. ${ }^{29}$ For every isochoric experiment, the amount of HTL process water was varied such that a similar pressure was reached at the different temperatures used. For the temperatures 673,723 , and $783 \mathrm{~K}$, the liquid volumes added were $8.5,6.3$, and $4.0 \mathrm{~mL}$, respectively. After the solution was added, the reactor was closed and purged with argon to remove oxygen before to be pressurized with $2.5 \mathrm{MPa}$ of argon. The batch reactor was then placed in a preheated sand bath (Cole-Parmer, IFB-51) and kept for a reaction time of $15 \mathrm{~min}$ counted down from the time the temperature in the batch reactor reached $623 \mathrm{~K}$. This reaction time protocol was defined to compensate for the different temperatures used and the different temperature ramps used during the batch reactor tests. This reaction time value was defined to be representative of the hydraulic retention time in the salt separator during the continuous test, estimated to be in the 10-12 min range but corrected to a higher value to compensate for the much faster heating ramp on the continuous setup than on the batch system. Once the reaction time was reached, the reactor was quenched by immersing it in a water bath at room temperature. Following that, the gas was sampled in an argon-purged gas sampling bag before being analyzed with a calibrated microGC (Inficon microGC 3000A). The volume of gas produced was calculated using the pressure and temperature measured within the reactor before and after the test. For the liquid sample, the batch reactor was opened and $4 \mathrm{~mL}$ of diethyl ether was added to dissolve and extract apolar organics. The reactor was then shaken vigorously before the two phases were sampled for further analysis. The test performed at $733 \mathrm{~K}$ was repeated once to confirm the repeatability of the tests.

\section{HPLC-HRMS Analysis}

The feed and brine samples, homogeneous aqueous solutions, were diluted 1:100 with ultrahigh purity water, filtered, and analyzed directly by HPLC-HRMS. The salt separator outlet sample was a fine emulsion of organics in an aqueous phase once sampled, the organic phase separating after ca. $30 \mathrm{~min}$. It was first mixed with ethyl acetate in the ratio $1: 1(\mathrm{v} / \mathrm{v})$ to extract the apolar organic compounds and dissolve tars. The resulting organic and water phases were separated by centrifugation and analyzed. Prior to the analysis, all samples were filtered $(0.22 \mu \mathrm{m})$. Blank runs were performed in between each analysis and subtracted from samples. The injection volume was $1 \mu \mathrm{L}$. The analysis was performed in a Thermo Scientific Dionex Ultimate 3000 Series RS system (Thermo Scientific) consisting of a pump, a column compartment, and an autosampler.

The chromatographic separation of compounds was carried out with the use of an Accucore RP-MS column $(150 \mathrm{~mm} \times 2.1 \mathrm{~mm}$, particle size $2.6 \mu \mathrm{m}$ ), from Thermo Scientific, with a Uniguard precolumn (Accucore RP-MS Defender Guards included; $2.1 \mathrm{~mm} \times 10 \mathrm{~mm}, 2.6$ $\mu \mathrm{m})$. The following gradient with mobile phase A ( $1 \mathrm{vol} \% \mathrm{MeOH}, 1 \mathrm{vol}$ $\%$ acetonitrile, and $0.2 \mathrm{vol} \%$ formic acid in water) and mobile phase $\mathrm{B}$ (100 vol \% MeOH) was applied as follows: $1 \% \mathrm{~B}(0-1 \mathrm{~min}) 1 \%-99 \% \mathrm{~B}$ (1-6 min), 99\% B (6-8 $\mathrm{min})$, followed by equilibration step and 99\%$1 \% \mathrm{~B}(8-8.2 \mathrm{~min}), 1 \% \mathrm{~B}(8.2-10 \mathrm{~min})$. The flow rate was set to $0.7 \mathrm{~mL}$. $\mathrm{min}^{-1}$, and the temperature of the column was kept constant at $323 \mathrm{~K}$. A heated electrospray ionization source (H-ESI, $3 \mathrm{kV}$ spray voltage) was used for the ionization of the analytes in positive and negative modes. Data acquisition was performed using a Thermo Scientific Q-Exactive hybrid quadrupole-orbitrap mass spectrometer controlled by Xcalibur 4.1 software. Mass spectra were acquired in full scan mode with an isolation window of $1 \mathrm{~m} / z$ from 50 to $750 \mathrm{~m} / z$. The resolution was 70000 at $m / z=200$. Raw mass spectral data files were collected in triplicate including a blank between each run.

\section{Data Processing and Mining}

The HPLC-HRMS data were imported into Compound Discoverer 3.1 software (Thermo Scientific) and processed with standard settings except for mass tolerance (set to $2.5 \mathrm{ppm}$ ). Chromatographic peaks detected in one of the input files but missing in others were checked by the "Fill Gaps" option. The composition (of a general formula $\mathrm{C}_{c} \mathrm{H}_{h} \mathrm{O}_{o} \mathrm{~N}_{n} \mathrm{~S}_{s}$ ) was predicted on the basis of exact mass and isotopic patterns and evaluated against MS/MS spectra. The identity of the compounds was determined where possible with mzCloud. ${ }^{30}$ Only features yielding formulas present in ChemSpider were used. ${ }^{31}$ The measured data, calculated features, and properties of the samples were used as an input to descriptive and differential statistics, as well as various nontarget data screening methods, such as

(1) The analysis and comparison of the hydrogen and oxygen content of the samples by van Krevelen plots, a graphicalstatistical method representing the molar oxygen-to-carbon ratios as a function of hydrogen-to-carbon ratios of the detected compounds. ${ }^{32}$ In such plot, each circle is proportional to the peak intensity of an identified compound. The color of the dot corresponds to the different compound classes according to the aromaticity index, where blue corresponds to aliphatic, orange to aromatic and red to condensed aromatic species. ${ }^{33}$

(2) Volcano plots, a type of scatter-plot that is used to identify changes in large data sets composed of replicate data, ${ }^{34}$ were used to identify statistically significant differences between the abundances of the molecular species detected in two different samples. The $x$-axis is the $\log _{2}$ of the fold-change and the $y$-axis is the statistical significance $\left(-\log _{10}[p\right.$-value $]$ obtained from a post hoc ANOVA analysis). The cutoff values were set to 2 for the fold-change and 1.3 for the statistical significance (corresponds to $p$-values $<0.05$ ). The terms "down-regulated", "nonaffected", and "up-regulated" are used for species whose abundance decreased, did not change, and increased in the pairwise comparison of the samples compositions, respectively. The analysis was used to assess the number of species affected by perturbations in the process parameters, as well as to create groupings of species used in the subsequent analysis.

(3) The double bond equivalent (DBE) of identified compounds was plotted with regards to their respective molecular weight (MW). The DBE was calculated as follows: $C-\left(\frac{H}{2}\right)+\left(\frac{N}{2}\right)+1$, where $C=$ number of carbon atoms, $H$ = number of hydrogen, and $N=$ number of nitrogen atoms. One 
DBE corresponds to one ring or one double bond. To estimate the input of each particular mass in DBE or MW distribution, the Kernel density estimation (KDE) was utilized. $\mathrm{KDE}$ is a nonparametric method for estimating the probability density function of a random variable. In this case, we used the Gaussian function as a density function as implemented in Scipy. ${ }^{35}$ It includes an automatic bandwidth estimation using Scott's rule. ${ }^{36}$ Additionally, we implemented a weighting of the density function in order to assess the different peak areas observed during mass spectrometry measurements. By applying this analysis strategy, no cutoffs are needed, and all measured data were used. The Python libraries SciPy, Numpy, Pandas, and Matplotlib were used for data processing and plotting, respectively. ${ }^{37}$

\section{Quantification of Carboxylates in Complex Organic Mixtures}

For the quantification of mono- and tricarboxylic acids, commercially available standards were used. With none of the identified dicarboxylic acid being commercially available, a semiquantitative analysis of the dicarboxylic acids was performed with an in-house method on the basis of ionization efficiency. ${ }^{38}$ This approach is based on the prediction of the ionization efficiency of a compound as a function of the mobile phase composition and carbon content in the molecule. The concentration was calculated from eq 1 , where area represents the mass spectrometry response and IE is the relative ionization efficiency of the compound:

$$
\text { concentration }=\frac{\text { area }}{\mathrm{IE}}
$$

The values for the IE were obtained by the experimental acquisition of different dicarboxylic acids at a given methanol concentration in the eluent.

\section{General Characterization Methods}

Carbon, Nitrogen, and Sulfur Elemental Analysis (CNS). CNS analysis was performed with an elemental analyzer (Vario EL cube, Elementar). Liquid (25-50 mg) and solid (5-15 mg) samples were burned at $1423 \mathrm{~K}$ in a quartz glass reactor with the help of a $\mathrm{WO}_{3}$ catalyst. In a second quartz glass reactor, $\mathrm{NOx}$ species were reduced to $\mathrm{N}_{2}$ by a Cu catalyst. Carbon was detected as $\mathrm{CO}_{2}$ and nitrogen as $\mathrm{N}_{2}$ with a thermal conductivity detector, while sulfur was measured as $\mathrm{SO}_{2}$ with an infrared detector. Sulfanilamide was used as a standard to determine the daily factor (theoretical content to actual content factor). For the analysis of $\mathrm{H}$ of dry solids, the water trap was removed. This was repeated at least four times for each sample to calculate the standard deviation.

Carbon Analysis-Offline and Online. The total carbon $\left(\mathrm{TC}_{\mathrm{wet}}\right)$, total organic carbon (TOC), and total inorganic carbon (TIC) of liquid samples were analyzed with a TOC analyzer (Dimatoc). The samples diluted to the calibrated concentration range and maintained under stirring were injected into a quartz glass reactor where they were burnt at $1123 \mathrm{~K}$ under a constant oxygen carrier gas flow $\left(200 \mathrm{~mL} \cdot \mathrm{min}^{-1}\right) \cdot \mathrm{CO}_{2}$ was detected with a nondispersive infrared (NDIR) detector for determining the TC. For measuring the TIC, the samples were injected into a 10 wt $\%$ solution of $\mathrm{H}_{3} \mathrm{PO}_{4}$ and the evolving $\mathrm{CO}_{2}$ was stripped with the oxygen carrier gas flow and transported to the NDIR detector. Then, the TOC was obtained by subtracting the TIC from the TC. The analysis was repeated around seven times for each sample (standard deviation evaluation). The TC, TOC, and TIC of the liquid samples collected during the experiments performed in KONTI-C were measured online by a TC/TIC analyzer (GE Analytical Instruments, Sievers InnovOx Online TOC Analyzer).

Ash Content of Biomass Samples. The ash content (wt \%) was determined by calcining the samples (ca. 10-25 g) in air and placed in a ceramic crucible, following this procedure: (1) $8 \mathrm{~h}$ at $393 \mathrm{~K}$, heating ramp of $5 \mathrm{~K} / \mathrm{min}$; (2) $2 \mathrm{~h}$ at $573 \mathrm{~K}$, heating ramp of $1 \mathrm{~K} / \mathrm{min}$; (3) $3 \mathrm{~h}$ $1173 \mathrm{~K}$, heating ramp of $5 \mathrm{~K} / \mathrm{min}$. The crucibles were then cooled to ca. $423 \mathrm{~K}$ and transferred to a desiccator until fully cold and were then weighted and compared with the empty crucible weight. For accurate measurements and standard deviation, the ash content was measured three times for each sample.

Dry Matter of the Feed and pH Determination. The dry matter content of the feed was determined by heating a sample $(10-20 \mathrm{~g})$ at $378 \mathrm{~K}$ in open air until no evolution of weight was detected. This was repeated 2-3 times for each sample (standard deviation evaluation). The $\mathrm{pH}$ measurements were performed with a calibrated $\mathrm{pH}$-meter (SCHOTT, Handylab pH/LF12).

Online Micro Gas Chromatography (microGC). The gas composition during the experiments performed on KONTI-C was measured online by a microGC (INFICON, 3000 Micro GC) with Ar as the carrier gas using a TCD. The gas samples were withdrawn automatically every $5 \mathrm{~min}$ and passed through three parallel columns (A, B, and $\mathrm{C}) . \mathrm{CH}_{4}, \mathrm{CO}$, and $\mathrm{H}_{2}$ were analyzed on column $\mathrm{A}$, whereas $\mathrm{CO}_{2}$ and $\mathrm{C}_{2+}$ were on column $\mathrm{B}$. Column $\mathrm{C}$ was semicalibrated (one calibration point only) for $\mathrm{H}_{2} \mathrm{~S}$, methylthiol, dimethylsulfide, and COS.

Inductively Coupled Plasma Optical Emission Spectroscopy (ICP-OES). Elemental screening and quantitative elemental analysis of aqueous samples were performed by an ICP-OES device (Agilent 715). The analyzer was calibrated with different dilutions of a multielement standard solution prepared from certified standards. The standards of the individual elements were purchased either from Ultra Scientific or from Merck. To allow element concentrations to be within the calibrated range and to fit the matrix of the samples to the matrix of the standard solution, the samples were diluted with $1 \mathrm{wt} \% \mathrm{HNO}_{3}$ by a factor of $10-600$ to compensate the high potassium concentration of some samples. All the solutions were filtered $(0.22 \mu \mathrm{m})$ before $1 \mathrm{wt} \%$ $\mathrm{HNO}_{3}$ solution was added. Each sample was injected three times, and the mean value is reported. The standard deviation of the three repetitions did not exceed $5 \%$.

\section{RESULTS AND DISCUSSION}

\section{Catalytic Hydrothermal Gasification}

Process Overview and Sample Composition. The cHTG experiment was run for a total of $22 \mathrm{~h}$, from which one steady state of about $4 \mathrm{~h}$ was studied in detail. The average temperatures at the top of the salt separator, at the sulfur trap, and in the gasification catalyst bed were $729 \pm 3,643-663$, and 648-667 K, respectively, for an average pressure of $28.9 \pm 0.1$ $\mathrm{MPa}$ (see the Supporting Information). Once the steady state was reached, samples were taken at the brine and process water outlets over long periods of time to obtain averaged representative samples, while the gas composition was continuously monitored using the micro-GC. Using online process data and off-line analysis results, mass balances were calculated and closed for most relevant elements (C, K, Na, N, S, $\mathrm{Mg}, \mathrm{Ca}, \mathrm{Ru}$, and $\mathrm{Zn}$ ) along with ash and chemical energy balances.

In addition to the main process effluents, samples between the salt separator and the catalytic reactor, referred to as "desalinated stream", were taken via a pair of computercontrolled pneumatic valves separated by a sampling loop to investigate salt carry-over and deposition in the trap and catalyst, leaching of $\mathrm{Ru}$ and $\mathrm{Zn} / \mathrm{Al}$ from the catalyst and the trap, respectively, and better understand the chemistry occurring in the salt separator.

The feed was converted into a synthetic natural gas and two liquid effluents, a clear odorless and colorless solution, that is the process water, and a mineral-rich brine. The brine consisted of a solid-free homogeneous solution. As presented in Table 2, its density and dry matter content were high, $1.15 \mathrm{~kg} \cdot \mathrm{L}^{-1}$ and 26.4 wt $\%$, respectively, compared to $1.03 \mathrm{~kg} \cdot \mathrm{L}^{-1}$ and $7.9 \mathrm{wt} \%$ for the feed. These values indicate a significant increase of dry matter content in the brine stream, as intended. The $\mathrm{pH}$ in this brine effluent was as high as 9.6, to be compared to the $\mathrm{pH}$ of the feed 
of 5.5, which coincides with a high concentration of carbonate in this effluent $\left(38 \mathrm{~g}_{\mathrm{CO}_{3}}{ }^{2-} \cdot \mathrm{L}^{-1}\right)$. This, along with the high ash content in the brine (13.0 wt \%), mostly composed of potassium, indicates an efficient salt separation but also the formation of carbonates in the salt separator, with the feed being free of it. This point will be further discussed below.

The level of organic carbon and the HHV of the brine are higher than expected. The reasons for such values are investigated below along with the means to minimize carbon and energy loss in the brine phase.

The process water has an ash content and a dry matter content below the detection limit of our methods, i.e., $<50 \mathrm{mg} \cdot \mathrm{L}^{-1}$ and $<0.001 \mathrm{wt} \%$, respectively. The data presented in Table 2 show a TOC value in the process water below $20 \mathrm{mg} / \mathrm{L}$, to be compared to the $34 \mathrm{~g} \cdot \mathrm{L}^{-1}$ in the feed, which confirms the high performance of the catalyst to effectively gasify organic compounds from the feed stream. Note that $\mathrm{HCl}$ was added continuously to the phase separator where the produced gas was separated from the process water in order to remove $\mathrm{CO}_{2}$ from the process water and allow for accurate online TIC/TOC measurements.

As shown in Figure 1 and Table 1, the SNG consists mainly of $\mathrm{CH}_{4}$ (55.5 vol \%), $\mathrm{CO}_{2}$ (42.1 vol \%), and $\mathrm{H}_{2}$ (2.4 vol \%), with

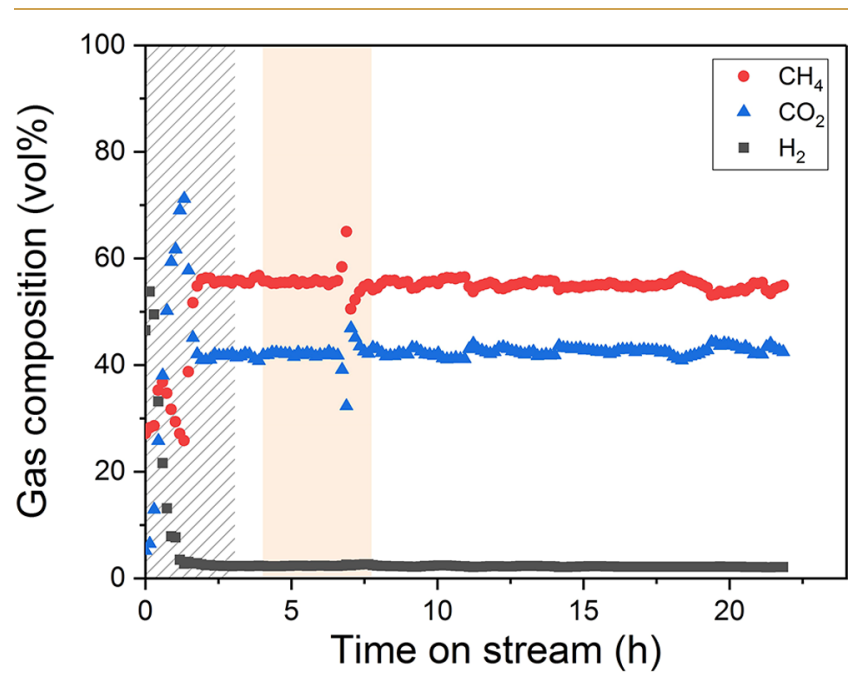

Figure 1. Evolution of SNG composition during cHTG of concentrated pine wood HTL process water. The hatched period corresponds to the ramp-up preceding the steady state. The pink zone corresponds to the steady-state period during which the samples were taken in order to establish the mass and energy balances. $\mathrm{C}_{2+}$ below $0.1 \mathrm{vol} \%$, CO below quantification limit $(<0.01 \mathrm{vol} \%)$.

traces of $\mathrm{C}_{2}-\mathrm{C}_{4}$ hydrocarbons $(0.02$ vol \%). Thanks to the gasification catalyst used, the gas composition is entirely controlled by thermodynamics and is thus mainly related to the concentration and composition of the organic matter, as well as to the temperature. A high temperature and a low organic carbon content, or in other words, a high concentration of water, promotes the formation of $\mathrm{H}_{2}$ at the expense of $\mathrm{CH}_{4}{ }^{7}{ }^{7,20,39}$ The composition of the gas was constant throughout the test. The spike observed at around $7 \mathrm{~h}$ of time on stream (Figure 1) corresponds to the moment the desalinated stream was sampled, leading to several sudden drops in flow and small fluctuations in pressure. The flow of gas was constant throughout the steady state, and the average volumetric gas flow rate was $0.54 \mathrm{NL}$. $\mathrm{min}^{-1}$. This value corresponds to about $34 \mathrm{NL} \cdot \mathrm{kg}_{\text {feed }}{ }^{-1}$ or 430 $\mathrm{NL} \cdot \mathrm{kg}_{\mathrm{DM}}{ }^{-1}$.
Table 1. Composition of the Raw Synthetic Natural Gas Produced during the Steady-State Period

\begin{tabular}{|c|c|c|}
\hline parameter & unit & value at steady state \\
\hline productivity $^{a}$ & $\mathrm{NL}_{\mathrm{SNG}} \cdot \mathrm{kg}_{\mathrm{DM}}^{-1}$ & $430 \pm 60$ \\
\hline HHV & $\mathrm{MJ} \cdot \mathrm{Nm}^{-3}$ & $21 \pm 5$ \\
\hline $\mathrm{CH}_{4}$ & vol \% & $56 \pm 3$ \\
\hline $\mathrm{CO}_{2}$ & vol \% & $42 \pm 3$ \\
\hline $\mathrm{H}_{2}$ & vol \% & $2.4 \pm 0.2$ \\
\hline $\mathrm{N}_{2}$ & vol \% & $<0.001$ \\
\hline $\mathrm{C}_{2} \mathrm{H}_{6}$ & ppmv & $123 \pm 8$ \\
\hline $\mathrm{C}_{3} \mathrm{H}_{8}$ & ppmv & $<100$ \\
\hline $\mathrm{C}_{4} \mathrm{H}_{10}$ & ppmv & $<100$ \\
\hline $\mathrm{CO}$ & ppmv & $<100$ \\
\hline $\mathrm{NH}_{3}$ & vol \% & n.m. \\
\hline $\mathrm{H}_{2} \mathrm{~S}$ & $\operatorname{vol} \% / \mathrm{mg}_{\mathrm{s}} \cdot \mathrm{m}^{-3}$ & $<0.001 /<14$ \\
\hline $\mathrm{O}_{2}$ & vol \% & $<0.001$ \\
\hline
\end{tabular}

${ }^{a}$ Quantity of SNG produced per kilogram of dry matter of feed.

The concentration of $\mathrm{CO}$ produced during the test was below $100 \mathrm{ppmv}$ (below the detection limit of our microGC), which reflects the high selectivity of the $\mathrm{Ru} / \mathrm{C}$ catalyst to convert the feed molecules to $\mathrm{CH}_{4}$ and $\mathrm{CO}_{2}$.

Analysis of the Feedstock (HTL Process Water). The general analysis of the HTL process water used for the cHTG test can be found in Table 2. As a result of the use of potassium hydroxide as a catalyst during HTL, the process water obtained is very rich in potassium but with a surprisingly low $\mathrm{pH}$ of 5.5. This amount of $\mathrm{KOH}$ results in a relatively high ash content (2.9 wt $\%$ on a wet basis, $37 \mathrm{wt} \%$ of the dry matter).

The Van Krevelen diagram, the double bond equivalent plot, and heteroatom class distribution of the feed are shown in Figure 2. The main share of molecules in the sample belongs to different unsaturated species with $\mathrm{H} / \mathrm{C}$ values ranging from 1 to 2 , and the DBE values are from 1 to 4 with a moderate level of oxygenation $(\mathrm{O} / \mathrm{C}$ values are from 0.1 to 0.5$)$. The molecular weight was found to be in the range from 100 to $200 \mathrm{~g} \cdot \mathrm{mol}^{-1}$ with a main share of molecules with MW values around $133 \mathrm{~g}$. $\mathrm{mol}^{-1}$. The detected compounds in the feed belong to $\mathrm{O}_{2}$ and $\mathrm{O}_{3}$ heteroatom classes with a relative abundance equal to $36 \%$ and $32 \%$, followed by the $\mathrm{O}_{1}, \mathrm{O}_{4}$, and $\mathrm{O}_{5}$ chemicals with shares of $14 \%, 12.5 \%$, and $4 \%$, respectively. The detection of the species with up to six oxygen molecules was possible; however, their relative abundance was $0.5 \%$. The main chemical classes observed in the feed sample were different phenolic species, cyclic and linear ketones and mono- and dicarboxylic acids. These classes of chemicals are typical for HTL aqueous phase derived from the hydrothermal liquefaction of ligno-cellulosic biomass. $^{40,41}$

Mass Balances. A Sankey diagram was superimposed on the simplified sketch of the unit (Figure 3). This diagram shows that total mass, carbon, and ash balances are closed within uncertainty (see details in the Supporting Information). About $50 \%$ of the carbon that was fed to the experimental unit was converted in the catalytic reactor to synthetic natural gas. Likewise, $44 \%$ of the carbon was extracted in the brine, with carbonates representing $10 \%$ of the carbon present in the brine. The recovery of carbon in the brine phase is much higher than expected considering that $23 \%$ of the process effluents were extracted as brine during the steady state. The HPLC-HRMS analysis of the brine phase indicated that most of the organic molecules are composed of different di- and tricarboxylates, 
Table 2. Chemical Composition (wet basis) of the Feed, Brine, and Process Water Produced during the Steady-State Period of the cHTG Experiment ${ }^{a}$

\begin{tabular}{|c|c|c|c|c|}
\hline sample ID & unit & feed & brine & process water \\
\hline \multirow[t]{2}{*}{ flow in } & $\mathrm{g} \cdot \min ^{-1}$ & $15.9 \pm 0.5$ & $3.6 \pm 0.2$ & $12.0 \pm 0.4$ \\
\hline & $\mathrm{kg} \cdot \mathrm{h}^{-1}$ & $0.95 \pm 0.03$ & $0.22 \pm 0.01$ & $0.72 \pm 0.03$ \\
\hline density & $\mathrm{kg} \cdot \mathrm{L}^{-1}$ & $1.03 \pm 0.01^{b}$ & $1.150 \pm 0.001$ & $\mathrm{~N} / \mathrm{A}^{c}$ \\
\hline dry matter (DM) & wt $\%$ & $7.9 \pm 0.8$ & $26 \pm 3$ & $<0.001$ \\
\hline total organic $\mathrm{C}^{d}$ & $\mathrm{~g}_{\mathrm{C}} \cdot \mathrm{L}^{-1}$ & $34 \pm 2$ & $66 \pm 4$ & $<0.02$ \\
\hline total C & $\mathrm{g}_{\mathrm{C}} \cdot \mathrm{L}^{-1}$ & $34 \pm 2$ & $73 \pm 4$ & $<0.02$ \\
\hline total $\mathrm{N}$ & $\mathrm{mg} \cdot \mathrm{kg}^{-1}$ & $<200$ & $<200$ & $<200$ \\
\hline $\mathrm{pH}$ & & $5.52 \pm 0.01$ & $9.63 \pm 0.01$ & $\mathrm{~N} / \mathrm{A}^{c}$ \\
\hline conductivity & $\mathrm{mS} \cdot \mathrm{cm}^{-1}$ & $39.8 \pm 0.1$ & $126 \pm 1$ & $\mathrm{~N} / \mathrm{A}^{c}$ \\
\hline ash content & wt $\%$ & $2.9 \pm 0.1$ & $13.0 \pm 0.9$ & $<0.0005$ \\
\hline \multirow[t]{2}{*}{ HHV (calorimetry) } & $\mathrm{MJ} \cdot \mathrm{kg}_{\mathrm{DM}}{ }^{-1}$ & $7.7 \pm 0.9$ & $6.9 \pm 0.1$ & $<0.01^{e}$ \\
\hline & $\mathrm{MJ} \cdot \mathrm{kg}^{-1 f}$ & $0.61 \pm 0.09$ & $1.82 \pm 0.03$ & $<0.001^{e}$ \\
\hline $\mathrm{HHV}$ (from COD) $)^{g}$ & $\mathrm{MJ} \cdot \mathrm{kg}^{-1}$ & $1.2 \pm 0.13$ & & $<0.001^{e}$ \\
\hline potassium $(\mathrm{K})$ & $\mathrm{mg} \cdot \mathrm{L}^{-1}$ & $21000 \pm 1000$ & $99000 \pm 5000$ & $89 \pm 9$ \\
\hline calcium (Ca) & $\mathrm{mg} \cdot \mathrm{L}^{-1}$ & $250 \pm 20$ & $4 \pm 2$ & $0.9 \pm 0.1$ \\
\hline magnesium (Mg) & $\mathrm{mg} \cdot \mathrm{L}^{-1}$ & $66 \pm 7$ & $17 \pm 2$ & $<0.008$ \\
\hline ruthenium $(\mathrm{Ru})$ & $\mathrm{mg} \cdot \mathrm{L}^{-1}$ & $<0.04$ & $<0.08$ & $1.1 \pm 0.4$ \\
\hline sulfur $(S)$ & $\mathrm{mg} \cdot \mathrm{L}^{-1}$ & $<60$ & $160 \pm 50$ & $<3$ \\
\hline $\operatorname{zinc}(\mathrm{Zn})$ & $\mathrm{mg} \cdot \mathrm{L}^{-1}$ & $5.4 \pm 0.6$ & $76 \pm 8$ & $0.20 \pm 0.02$ \\
\hline
\end{tabular}

${ }^{a}$ Conditions: maximum salt separator temperature, $729 \pm 3 \mathrm{~K}$; gasification reactor temperature: $648-667 \mathrm{~K}$, pressure, $28.9 \pm 0.1 \mathrm{MPa}$. ${ }^{b}$ Determined by the Coriolis mass flow meter of the setup, at $29 \mathrm{MPa}$. ${ }^{c}$ Process water acidified with $\mathrm{HCl}$ to decrease carbonate level in the process water. ${ }^{d}$ Calculated according to the equation TOC $=\mathrm{TC}-\mathrm{TIC}$. ${ }^{e}$ Based on the concentration of ammonium and organic carbon. ${ }^{f} \mathrm{Calculated}$ from the $\mathrm{HHV}$ measured by calorimetry and the dry matter. ${ }^{g}$ Calculated from the chemical oxygen demand.
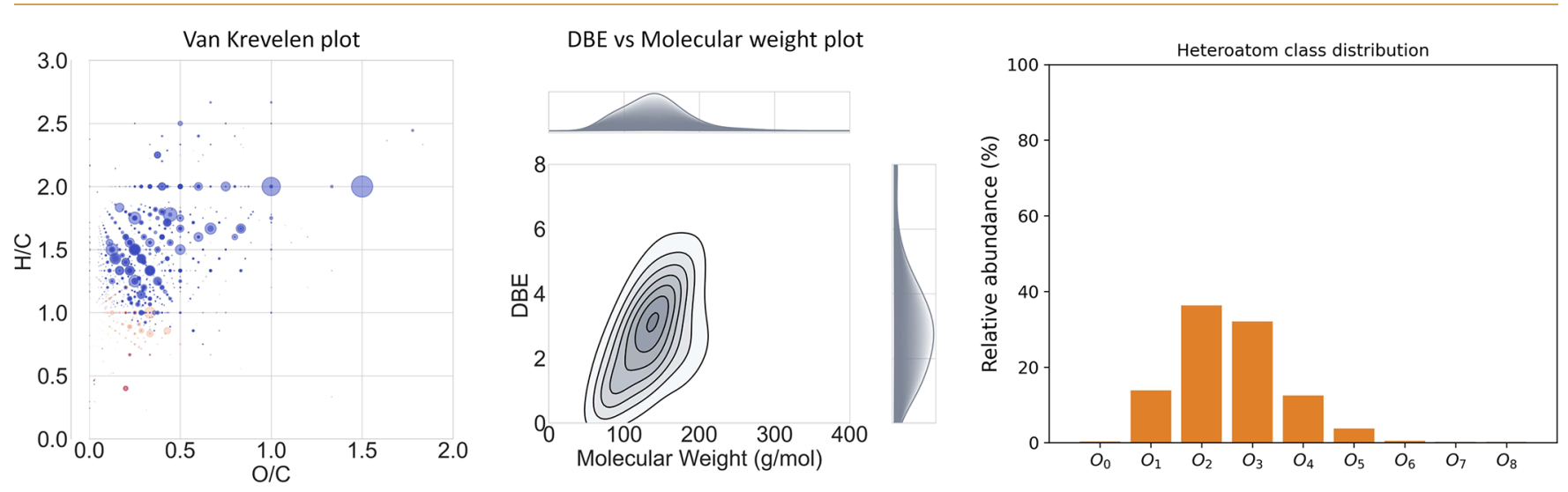

Figure 2. Chemical composition of the feed (HTL process water) represented by Van Krevelen plot, DBE versus molecular weight, and heteroatom distributions. The main share of the detected species in the sample belongs to different phenolics species, cyclic and linear ketones and mono- and dicarboxylic acids.

making up the significant loss of carbon in the brine effluent. This observation is described in more detail below.

The mass balances of the ashes indicate that $96 \pm 1 \%$ of the ash was extracted in the brine stream, with $97 \pm 1 \%$ and $96 \pm 1 \%$ of the two major components potassium and sodium, respectively, being recovered in that effluent (see Figure 4). Iron was also efficiently extracted in the brine stream. The mass balances of earth alkaline metals, however, indicate a different behavior. From 235 and $63 \mathrm{mg} \cdot \mathrm{h}^{-1} \mathrm{Mg}$ and $\mathrm{Ca}$ fed in, respectively, only $5 \%$ and $1 \%$ were recovered in the two outlets of the salt separator (Figure 4). This is indicative of the deposition and accumulation of these elements in the separation vessel, pointing to a selective precipitation of salts made up by these cations, possibly as carbonates or hydroxides. This deposition surprisingly occurred despite the high concentration of potassium that has been shown to improve the separation efficiency for many cases of salt mixtures. ${ }^{13,15,42}$ The concentrations of magnesium and calcium observed in the desalinated stream are 0.1 and $2.1 \mathrm{mg} \cdot \mathrm{L}^{-1}$, respectively. Considering that the highest temperature in the salt separator was $729 \pm 3 \mathrm{~K}$ (average temperature, near the desalinated stream outlet), a corresponding density of $134 \mathrm{~kg} \cdot \mathrm{m}^{-3}$ for pure water can be estimated. ${ }^{29}$ Solubilities of $0.01 \mathrm{ppm}_{\mathrm{Mg}}$ and 0.01 $\operatorname{ppm}_{\mathrm{Ca}}$ are expected for $\mathrm{Mg}(\mathrm{OH})_{2}$ and $\mathrm{CaCO}_{3}$ at this density, respectively, ${ }^{43}$ indicating that the presence of other anions might influence the solubility of the cations. Note that the presence of organics and gas formed from the gasification of organics would impact the density - and consequently the solubility - as well. ${ }^{44}$ Operating this vessel at a higher temperature and lower pressure would allow for even lower concentrations in the top of the 


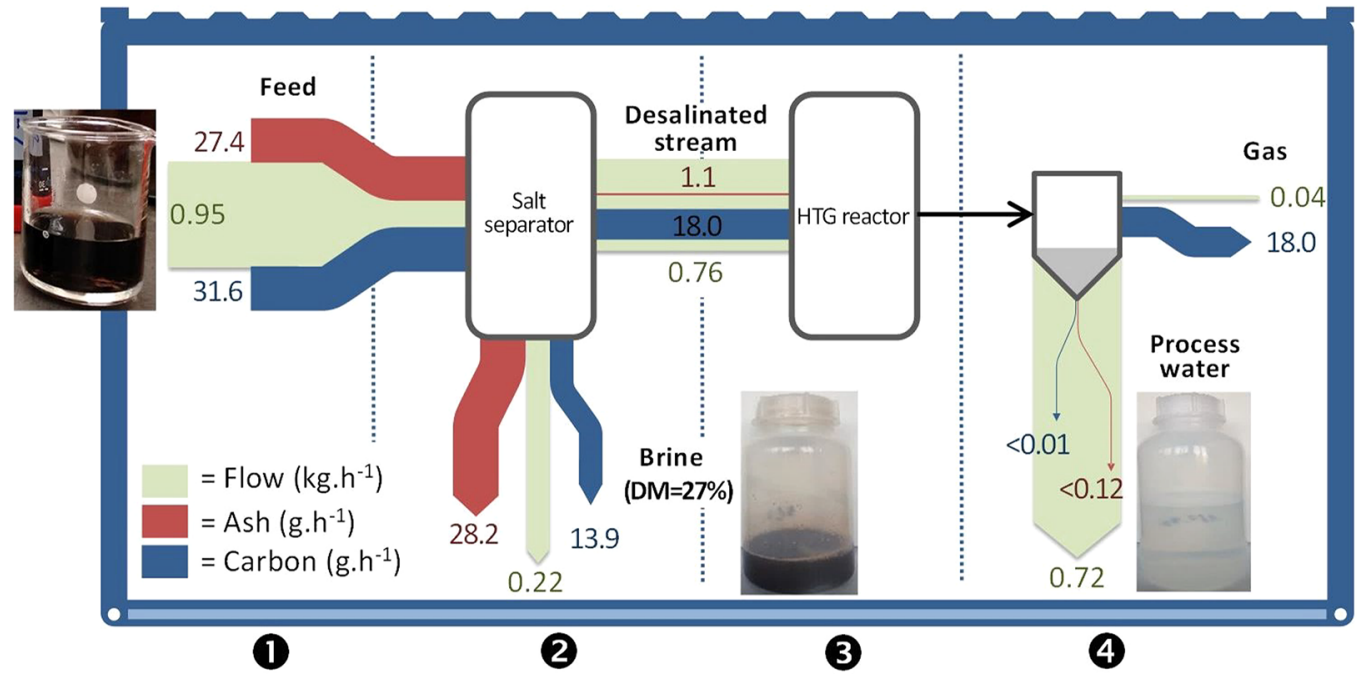

Figure 3. Sankey diagram of the ash, carbon, and total mass flows, throughout the catalytic hydrothermal gasification testing unit using pine wood HTL process water concentrated by recycling. Conditions: $29 \mathrm{MPa}$; temperature, $653-733$ (salt separator) and $653-673 \mathrm{~K}$ (catalytic reactor); $0.9 \mathrm{~kg}_{\text {feed }}$. $\mathrm{h}^{-1}, 8 \mathrm{wt} \% \mathrm{DM}$. The first section is the high-pressure feeding section, the second is the salt separation unit, the third is the catalytic hydrothermal gasification unit, and the fourth is the phase separation yielding synthetic natural gas.

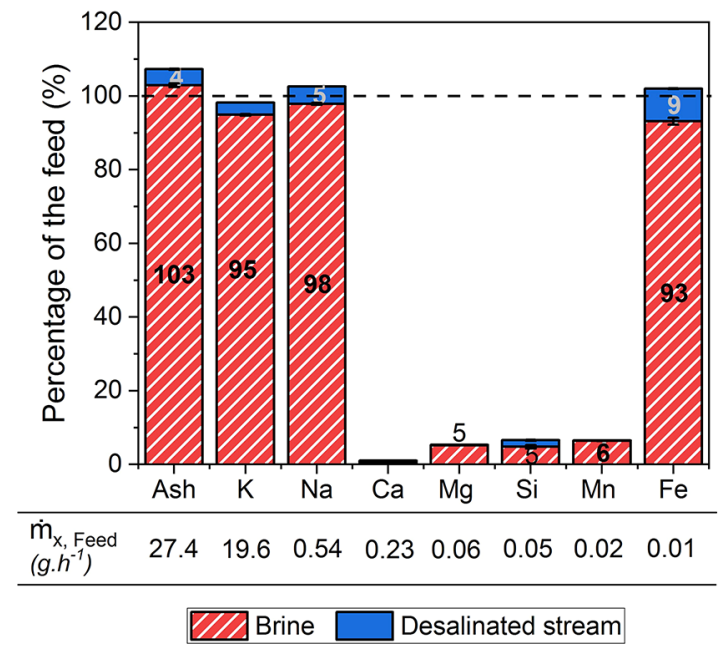

Figure 4. Percentage of ash and the main cations recovered in the two effluents exiting the salt separator, i.e., the brine and the desalinated stream, during cHTG of concentrated pine wood HTL process water.

separation vessel and hence better upconcentration of salts in the brine stream.

While the concentration of potassium in the brine is very high $\left(2.5 \mathrm{~mol} \cdot \mathrm{L}^{-1}\right)$, the concentration of the equivalent anionic charges is very low with $0.26 \mathrm{~mol}_{\text {charge }} \cdot \mathrm{L}^{-1}$ of carbonate $(\mathrm{P}, \mathrm{N}, \mathrm{S}$, or $\mathrm{Cl}$ are below the detection limit), leaving an ionic balance widely unclosed (90\% missing, see Table 5). This point was further investigated below using HPLC-HRMS analysis of the brine. Note that the flow of carbonate coming out in the brine was much higher than that fed in (see Table 2), indicating an important decarboxylation of the organics present in the feed occurring in the salt separator.

The difference in the flow rates of potassium and sodium in and out of the gasification reactor (desalinated stream and process water, respectively, see the Supporting Information) indicates an accumulation of alkaline metals most likely in the reactor on both the sulfur trap and the catalyst. This accumulation of minerals corresponds to ca. $1.1 \mathrm{~g}$ of inorganic compounds depositing every hour (see Figure 3 and the
Supporting Information). The presence of $\mathrm{CH}_{4}, \mathrm{CO}_{2}$, and $\mathrm{H}_{2}$ in the catalytic gasification reactor (with an average fluid temperature of $668 \mathrm{~K}$ ) can significantly decrease the fluid density, ${ }^{44}$ possibly enough to reach the density of the fluid at the hottest point of the salt separator. Some salt precipitation in the catalytic reactor could hence occur. However, a significant variation of $\mathrm{K}$ and $\mathrm{Na}$ concentration during the $22 \mathrm{~h}$ test discards this possibility. With the vessel being filled with $484 \mathrm{~g}$ of activated carbon supported $\mathrm{Ru}$ catalyst having a pore volume of $0.6 \mathrm{~cm}^{3} \cdot \mathrm{g}^{-1}$, mostly microporous, the hypothesis of the reversible adsorption of minerals in the micropore network of the support can also be put forward. The impact of this accumulation of inorganic compounds on the catalyst performance remains unclear as the catalyst operates under a thermodynamic regime. The concentration of $\mathrm{K}$ and $\mathrm{Na}$ in the process water increased by 7 - and 40 -fold, respectively, from the first steady state (time on stream $4-8 \mathrm{~h}$ ) to the second (time on stream 9-24 h). During the first steady state, $90 \%$ of $\mathrm{K}$ accumulated in the catalyst vessel, while only $14 \%$ did so during the second steady state. Note that during this second steady state, the conditions were sensibly the same, with the exception of a ca. $60 \%$ higher brine flow. In addition, the concentrations of $\mathrm{K}$ and $\mathrm{Na}$ measured in the process water during the purge with water after the test (with supercritical water and while cooling) indicate an important release of these cations, allowing to recover $4 \mathrm{~g}$ of the $6 \mathrm{~g}$ of $\mathrm{K}$ estimated to have accumulated in the reactor. These observations support the hypothesis of a reversible salt accumulation in the sulfur trap and gasification catalyst bed. In either case, this accumulation of salts in the cHTG reactor could be decreased by favoring a lower density in the salt separator.

The analysis of $\mathrm{Ru}$ flowing in and out of the reactor indicated a flow of $0.8 \pm 0.4 \mathrm{mg}_{\mathrm{Ru}} \cdot \mathrm{h}^{-1}$ exiting the reactor $\left(1.1 \pm 0.4 \mathrm{mg}_{\mathrm{Ru}}\right.$. $\mathrm{L}^{-1}$ in the process water, see the Supporting Information) over an average of $4 \mathrm{~h}$. This value remained in the same range in the sample collected from time on stream $9-24 \mathrm{~h}$. This is to be compared to the $24 \mathrm{~g}$ of ruthenium present in the reactor. However, this is not negligible for long operation time and triggered further investigations. ${ }^{19}$ The flow of $\mathrm{Al}$ and $\mathrm{Zn}$, which are major constituents of the (sulfur-) trap, barely varied from 
the inlet to the outlet of the catalytic reactor. It can hence be concluded that negligible amounts of these elements leached out of the reactor during the test, but an accumulation of $\mathrm{Zn}$ and $\mathrm{Al}$ has already been observed to occur on the microporous catalyst placed downstream of the trap. ${ }^{17}$

\section{Higher Heating Value and Chemical Energy Balance}

Evaluation of the Higher Heating Value of Feedstocks Rich in Volatile Organic. The evaluation of the chemical energy balance using the higher heating value (HHV) measured from the feed and brine dry matters and calculated from the gas composition (see Table 4) indicates that $68 \pm 12 \%$ of the feed chemical energy ends up in the brine effluent and $116 \pm 30 \%$ in the gas stream. The exceeding balance might come from the loss of volatile organics during the drying of the feed ( $\mathrm{HHV}$ analysis performed by calorimetry on the dry matter). Indeed, the $\mathrm{pH}$ of the solution is 5.5 and the solution contains a significant amount of carboxylic acids and low molecular weight molecules that are likely to evaporate when drying the sample.

Several empirical equations exist to calculate the HHV of an organic mixture, but they all use the chemical composition of the corresponding dry matter. ${ }^{45-47}$ Tillmann et al. derived an empirical correlation between HHV and the carbon content of biomass (dry matter basis). ${ }^{45,48}$ This equation, being only based on the carbon content, has a limited field of application (here biomass only) and presents limited accuracy but can nevertheless give a good estimate. From this equation, the following equation can be derived assuming a negligible loss of volatile carbon:

$$
\begin{aligned}
& \operatorname{HHV}\left(\mathrm{MJ} \cdot \mathrm{kg}_{\text {wet }^{-1}}\right) \\
& \quad=0.4373 \times \mathrm{TC}_{\text {wet }}-0.0167 \times \mathrm{DM}
\end{aligned}
$$

where wet refers to wet biomass, $\mathrm{TC}_{\mathrm{wet}}$ corresponds to the total carbon concentration in the wet biomass (wt \%), and DM is the dry matter content (wt \%).

Another approach is to use the correlation between the chemical oxygen demand (COD) of organic substances and their higher heating values. This correlation is displayed in Figure 5 for a large selection of pure organic compounds. Their theoretical COD was calculated from eq 3, obtained from the oxygen coefficient given in the chemical equation describing the

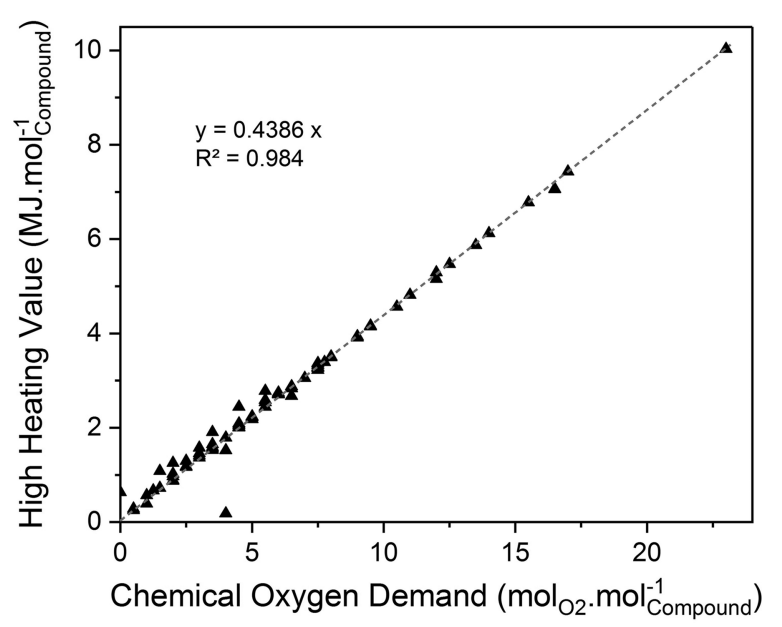

Figure 5. Correlation of the higher heating value (absolute value of the heat of combustion at standard conditions, $\Delta H_{\mathrm{c}}^{\circ}$ ) of various pure compounds with their theoretical chemical oxygen demand. oxidation occurring during a COD measurement with potassium dichromate (eq 4).

$$
\begin{aligned}
& \operatorname{COD}\left(\text { mole }_{\mathrm{O}_{2}} \cdot \text { mole }_{\text {compound }^{-1}}\right) \\
& =c+\frac{1}{4} h-\frac{3}{4} n-\frac{1}{2} o
\end{aligned}
$$

where compound refers to $\mathrm{C}_{c} \mathrm{H}_{h} \mathrm{~N}_{n} \mathrm{O}_{o}$ in the following equation:

$$
\begin{gathered}
\mathrm{C}_{c} \mathrm{H}_{h} \mathrm{~N}_{n} \mathrm{O}_{o}+\left(c+\frac{1}{4} h-\frac{3}{4} n-\frac{1}{2} o\right) \mathrm{O}_{2} \\
\rightarrow c \mathrm{CO}_{2}+\left(\frac{1}{2} h-\frac{3}{2} n\right) \mathrm{H}_{2} \mathrm{O}+n \mathrm{NH}_{3}
\end{gathered}
$$

Note that in this equation, nitrogen is assumed to be converted to ammonia, while, when measuring, $\mathrm{HHV} \mathrm{N}_{2}$ is formed, which can be a source of error. Sulfur is not present in the equation as it is assumed to be converted to $S(0)$, hence not impacting the oxygen coefficient in the equation.

On the basis of the linear correlation between COD and HHV presented in Figure 5, the following equation can be derived to calculate the HHV of wet biomass from its measured chemical oxygen demand:

$$
\operatorname{HHV}\left(\mathrm{MJ} \cdot \mathrm{kg}_{\mathrm{wet}^{-1}}\right)=\frac{0.439 \times \mathrm{COD}}{\rho_{\text {solution }}}
$$

where COD stands for chemical oxygen demand in mole $\mathrm{O}_{2} \cdot \mathrm{L}^{-1}$ and $\rho_{\text {solution }}$ stands for the density of the solution in $\mathrm{kg}_{\text {wet }} \cdot \mathrm{L}^{-1}$.

The validity of this equation was verified by plotting the HHV vs the COD of real biomass, real liquid and solid fuels, and wastes from ref 45 and internal measurements. For that, the $\mathrm{C}$, $\mathrm{H}, \mathrm{N}$, and $\mathrm{O}$ compositions (dry matter basis) were used to calculate the COD $\left(\right.$ mole $_{\mathrm{O}_{2}} \cdot$ mole $\left._{\mathrm{CHNO}}{ }^{-1}\right)$ as explained above. A good correlation was also obtained between the relative $\mathrm{HHV}$ $\left(\mathrm{MJ} \cdot\right.$ mole $\left._{\mathrm{CHNO}}{ }^{-1}\right)$ and the calculated COD for a broad variety of dry and wet biomass with an $R^{2}$ of 0.97 and a slope of 0.436 , very similar to the one obtained with model compounds (see the Supporting Information). Note that the linear fit was best without an intercept of 0 , which might be an effect of the inaccurate estimation of the oxygen content in the dry matter. Indeed, oxygen content is often calculated by difference using the ash, $\mathrm{C}, \mathrm{H}, \mathrm{N}$, and $\mathrm{S}$ content instead of direct measurement. The ash containing oxygen also, oxygen content in the dry matter is always underestimated.

Note that high levels of reduced inorganic compounds in some samples may interfere with the determination of COD (nitrite, chloride, sulfide, ferrous iron). These interferences can be eliminated by the addition of complexing/precipitating reagents appropriate for COD measurement. Further note that this equation is suitable only if the organics present can be readily oxidized by the standard COD measurement procedure using potassium dichromate under acidic conditions. For instance, the presence of organics in a solid form, e.g., wood, char, might lead to an underestimation of the COD. The HTL process water is perfectly compatible with this approach because it is composed mainly of dissolved organics with only traces of organic solids, nitrogen, and sulfur.

As a conclusion, in case the HHV calculated from eq 2, using carbon concentration from the wet biomass, deviates from the $\mathrm{HHV}$ measured on the dry matter, one should consider that the measured higher heating value might have been underestimated. 
In this case, one should measure COD on the wet sample and use eq 5 to determine HHV.

Chemical Energy Balance. Using eqs 2 and 5, similar HHV values of $1400 \pm 200 \mathrm{~kJ} \cdot \mathrm{L}^{-1}$ were obtained, which is more than 2-fold greater than the HHV measured on the dry matter (see Table 3). For the brine sample, the HHV calculated from eq 2

Table 3. HHV of the Feed and the Brine Measured and Calculated Using Equations 2 and 5

\begin{tabular}{|c|c|c|c|}
\hline sample ID & unit & feed & brine effluent \\
\hline \multirow[t]{2}{*}{ measured HHV } & $\mathrm{kJ} \cdot \mathrm{L}^{-1 a}$ & $620 \pm 80$ & $2090 \pm 90$ \\
\hline & $\mathrm{MJ} \cdot \mathrm{kg}_{\mathrm{DM}}{ }^{-1}$ & $7.7 \pm 0.9$ & $6.9 \pm 0.3$ \\
\hline \multirow[t]{2}{*}{ HHV calculated from $\mathrm{COD}^{b}$} & $\mathrm{~kJ} \cdot \mathrm{L}^{-1}$ & $1400 \pm 200$ & n.d. \\
\hline & $\mathrm{MJ} \cdot \mathrm{kg}_{\mathrm{DM}}{ }^{-1}$ & $16 \pm 3$ & n.d. \\
\hline \multirow[t]{2}{*}{ HHV calculated from $\mathrm{TC}_{\text {wet }}{ }^{c}$} & $\mathrm{~kJ} \cdot \mathrm{L}^{-1}$ & $1400 \pm 200$ & $2700 \pm 500$ \\
\hline & $\mathrm{MJ} \cdot \mathrm{kg}_{\mathrm{DM}}{ }^{-1}$ & $17 \pm 2$ & $9 \pm 2$ \\
\hline
\end{tabular}

${ }^{a}$ Calculated from the HHV of the dry matter and the dry matter content. ${ }^{b}$ Calculated from eq $5 .{ }^{c}$ Calculated from eq 2.

was found to be $2700 \pm 500 \mathrm{~kJ} \cdot \mathrm{L}^{-1}$, while the one measured was $2090 \pm 90 \mathrm{~kJ} \cdot \mathrm{L}^{-1}$. The smaller difference can be explained by the high $\mathrm{pH}$ of the brine ( $\mathrm{pH}$ 9.6) limiting the evaporation of volatile carboxylic acids but also possibly by a lower concentration of volatile organic compounds.

The chemical energy balance was calculated using the HHV calculated from eq 2 from both the feed and the brine. The obtained chemical energy flows allow to nicely close the chemical energy balance (95\%) and indicate a loss of $41 \%$ of chemical energy in the brine, comparable to that of total carbon (44\%), while approximately $54 \%$ of the chemical energy ends up in the synthetic natural gas (see Table 4).

Analysis of the Influent and Effluent of the Salt Separator by HPLC-HRMS

Chemical Composition of the Salt Separator Effluents. The in-depth characterization of the outlet streams (brine and desalinated stream) of the salt separator was performed to shed light on the organic species converted or formed during the desalination process step. The species detected in the mass spectra of the brine stream are represented by a Van Krevelen diagram (Figure 6). The detected compounds have similar $\mathrm{H} / \mathrm{C}$ and $\mathrm{O} / \mathrm{C}$ ratios to those of the feed (see Figure 2) mostly in the ranges $1.0-1.8$ and $0.1-0.5$, respectively, but with a more dominant share of oxygenated species (see also the Supporting Information). The double bond equivalent distribution over the molecular weight distribution is comparable to that of the feed but with a prominent shoulder toward higher molecular weights $\left(180-200 \mathrm{~g} \cdot \mathrm{mol}^{-1}\right)$ and lower DBE values. The heteroatom class distribution of the brine sample showed an increase in the abundance of the compounds with a higher number of oxygen atoms in the molecule in comparison with the feed, in particular for $\mathrm{O}_{4+}$. The relative abundances of $\mathrm{O}_{4}, \mathrm{O}_{3}$, and $\mathrm{O}_{2}$ classes were found to be $43 \%, 26 \%$, and $22 \%$ followed by $\mathrm{O}_{1}, \mathrm{O}_{5}$, and $\mathrm{O}_{6}$ with $4 \%, 3 \%$, and $2 \%$, respectively.

In parallel, the compounds that were found in the aqueous phase of the desalinated stream mainly consisted of aliphatic, mildly oxygenated species, with $\mathrm{O} / \mathrm{C}$ values located between 0 and 0.4 and $\mathrm{H} / \mathrm{C}$ values from 1 to 2.5 (Figure 6). The DBE and molecular weight distribution was found to be close to that of the feed with, however, a shoulder at a higher molecular weight, i.e., 170-200 $\mathrm{g} \cdot \mathrm{mol}^{-1}$ and DBE 2-3. The heteroatom class distribution was clearly shifted toward a lower number of oxygen in the molecule in comparison with the feed with significantly less $\mathrm{O}_{3+}$ and three times more $\mathrm{O}_{1}$. For the diethyl ether extracted compounds from the desalinated stream (see the Supporting Information), nearly only $\mathrm{O}_{1}$ was detected, but interestingly, no $\mathrm{O}_{0}$ was detected, which results from the low ionization efficiency of aliphatic chains with the use of electrospray ionization. As expected, the apolar organics in the desalinated stream have low $\mathrm{O} / \mathrm{C}$ ratios mainly in the $0.05-0.10$ range, while their $\mathrm{H} / \mathrm{C}$ ratios range from 1.1 to 1.6 , while the DBE clearly goes toward higher values when compared to the feed.

To further understand the differences in chemical composition between brine and feed samples, we used a volcano plot analysis. This statistical method was used to separate compounds dominantly present in the brine sample (upregulated) from those dominantly present in the feed sample (down-regulated, see the Supporting Information). A Van Krevelen diagram was then drawn for these two sets of compounds and is shown in Figure 7. One sees that the species that are much more present in the brine phase than in the feed (up-regulated) are highly oxygenated with a broad range of $\mathrm{O} / \mathrm{C}$ ratios $(0.2-1)$. The compounds that had higher intensity in the feed than in the brine (down-regulated) have rather narrow $\mathrm{O} /$ $\mathrm{C}$ values ranging from 0.15 to 0.4 . This, coupled to the high share of carbon ending up in the brine, suggests that a separation of organics is occurring in the salt separator and/or a more severe deoxygenation (decarboxylation, decarbonylation, dehydration) of the desalinated stream, seeing higher temperature than the brine.

A more detailed look at the brine mass spectra revealed the high abundance of a large variety of dicarboxylic acids, and the most abundant compounds are shown in Figure 8. They were found to correspond to around $35 \%$ of the total abundance in the mass spectra of the sample.

Ionic Balance and Link with Gasification Efficiency. Table 5 presents the ionic balance in and out of the salt

Table 4. Total Carbon Mass Balance and Measured and Calculated Chemical Energy Flow Balances during cHTG of HTL Process Water

\begin{tabular}{|c|c|c|c|c|c|c|}
\hline & unit & feed & brine effluent & process water effluent & gas effluent & total effluents out \\
\hline \multirow[t]{2}{*}{ total C } & $\mathrm{g}_{\mathrm{c}} \cdot \mathrm{h}^{-1}$ & $31 \pm 1$ & $14 \pm 1$ & $<\mathrm{LoD}$ & $16 \pm 5$ & $30 \pm 5$ \\
\hline & $\%$ & & $44 \pm 3$ & & $50 \pm 13$ & $94 \pm 14$ \\
\hline \multirow[t]{2}{*}{ measured HHV } & $\mathrm{J} \cdot \mathrm{s}^{-1}$ & $160 \pm 30$ & $110 \pm 20$ & $<\mathrm{LoD}$ & $190^{a} \pm 50$ & $300 \pm 50$ \\
\hline & $\%$ & & $70 \pm 20$ & & $116 \pm 30$ & $180 \pm 50$ \\
\hline \multirow[t]{2}{*}{ HHV calculated from $\mathrm{TC}_{\text {wet }}(\mathrm{eq} 2)$} & $\mathrm{J} \cdot \mathrm{s}^{-1}$ & $347 \pm 40$ & $140 \pm 20$ & $<\mathrm{LoD}$ & $\mathrm{N} / \mathrm{A}$ & $330 \pm 50$ \\
\hline & $\%$ & & $41 \pm 7$ & & $54^{b} \pm 16$ & $95 \pm 18$ \\
\hline
\end{tabular}

${ }^{a}$ The HHV of the gas effluent is calculated from the gas composition measured by microGC. ${ }^{b}$ Percentage calculated using the gas effluent measured composition and the HHV individual gas. 

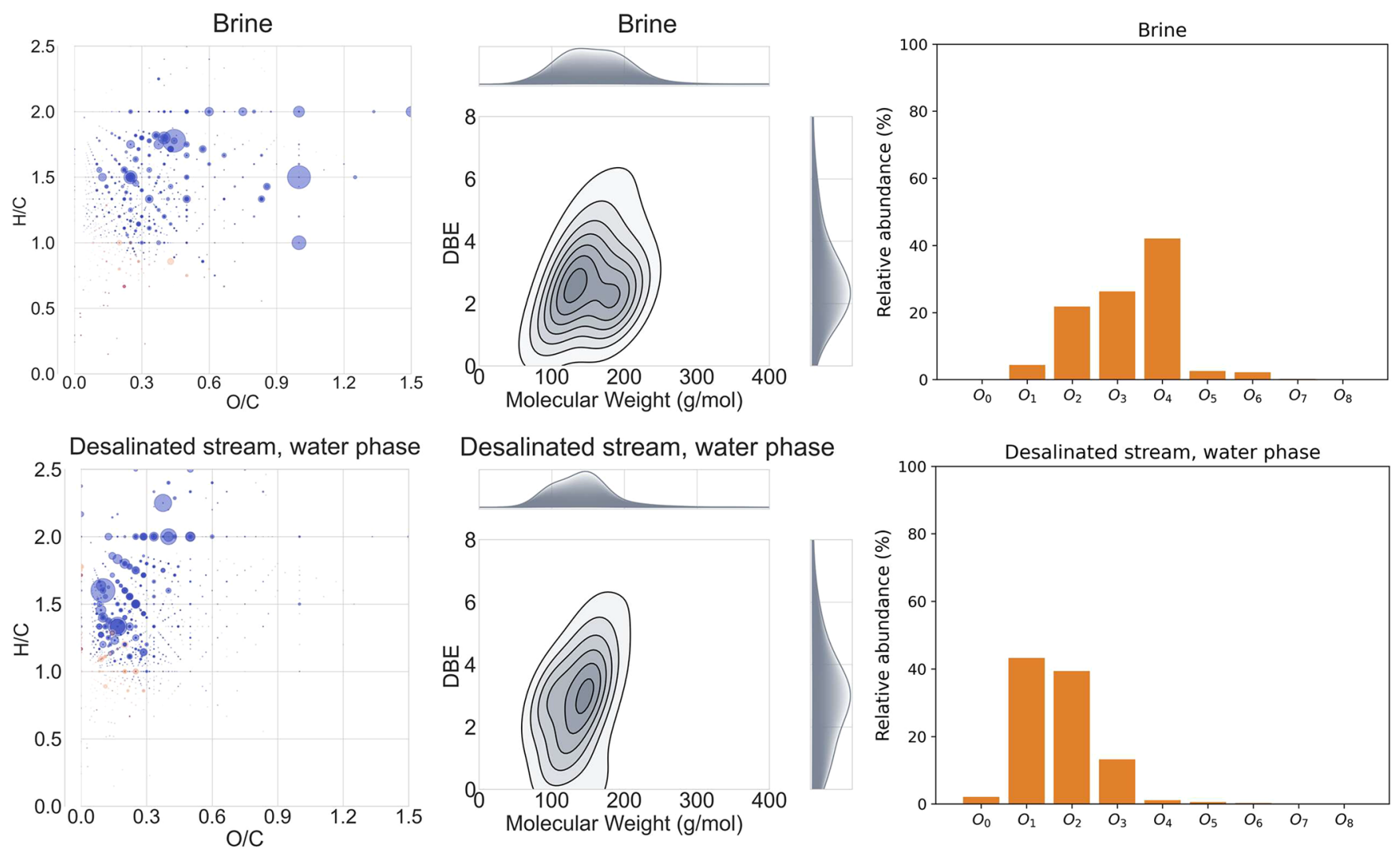

Figure 6. Van Krevelen diagram, DBE vs molecular weight, and heteroatom class distributions of the brine and of the water phase of the desalinated stream.
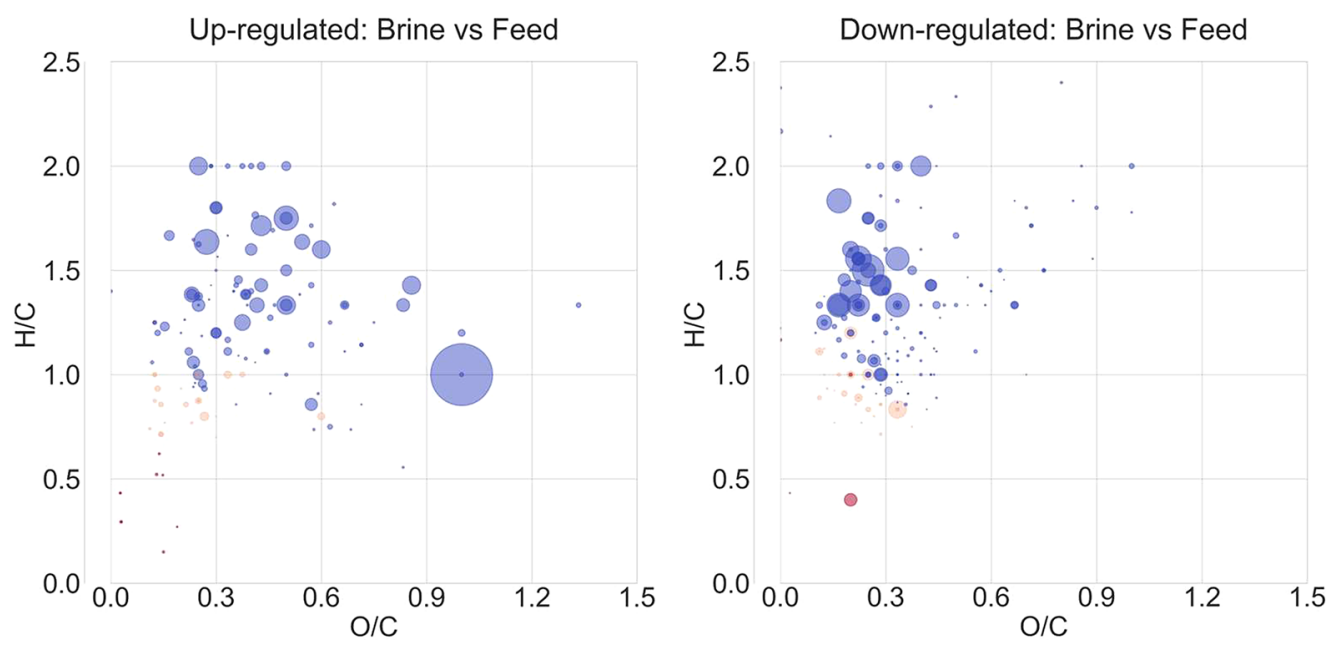

Figure 7. Van Krevelen diagram of the up- and down-regulated species derived from the volcano plot analysis of the feed and brine samples.

separator. The cation/anion ratio in the feed is widely unbalanced with the inorganic anions accounting only for ca. $1 \%$ of the balance. In the brine, carbonates make up $10 \pm 1 \%$ of the ion balance, pointing to the decarboxylation of organics in the salt separator.

As mentioned earlier, the carbon concentration in the brine is surprisingly high, indicating a significant loss of carbon in this effluent, which limits the carbon gasification efficiency to $54 \%$. The chemical energy balance follows the carbon mass balance. In order to help closing the ion balance, the main carboxylates identified in the brine were quantified by HPLC-HRMS by combining the standard substance-free method and direct quantification with the use of authentic standards. The cumulative carbon-based concentration of the main carboxylates identified by HPLC-HRMS can be found in Figure 9, along with the total organic carbon. About $72 \%$ of the TOC present in the brine could be assigned to carboxylates.

In addition, it was found that carboxylates account for $53 \pm$ $6 \%$ of the anionic charges in total (see Table 5), giving a total of $63 \pm 7 \%$ of anions identified in the brine. It can be hypothesized that the main part of the $37 \%$ missing anions is covered by the $28 \%$ of organics yet unidentified by HPLC-HRMS, keeping in mind the uncertainty of the carboxylate quantification. 


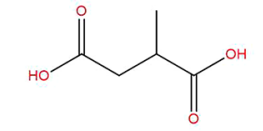

2-methylsuccinic acid Chemical Formula: $\mathrm{C}_{5} \mathrm{H}_{8} \mathrm{O}_{4}$
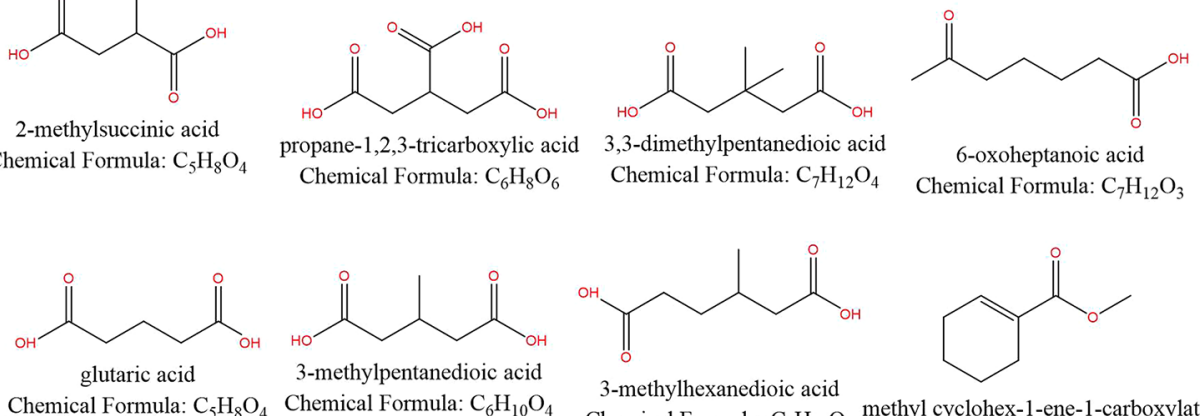
3-methylhexanedioic acid
Chemical Formula: $\mathrm{C}_{7} \mathrm{H}_{12} \mathrm{O}_{4}$ methyl cyclohex-1-ene-1-carboxylate<smiles>O=C(O)CCCCCCC(=O)O</smiles>

octanedioic acid Chemical Formula: $\mathrm{C}_{8} \mathrm{H}_{14} \mathrm{O}_{4}$

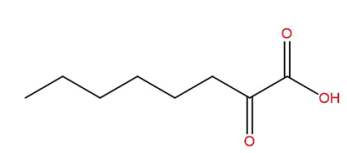

2-oxooctanoic acid Chemical Formula: $\mathrm{C}_{8} \mathrm{H}_{14} \mathrm{O}_{3}$

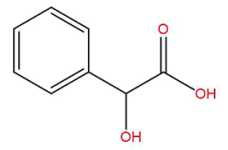

2-hydroxy-2-phenylacetic acid Chemical Formula: $\mathrm{C}_{8} \mathrm{H}_{8} \mathrm{O}_{3}$ Chemical Formula: $\mathrm{C}_{8} \mathrm{H}_{12} \mathrm{O}_{2}$

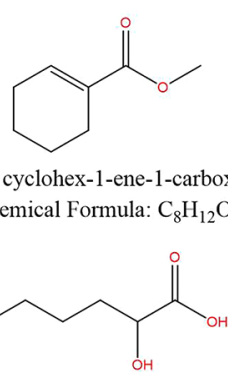

2-hydroxy-6-oxononanoic acid Chemical Formula: $\mathrm{C}_{9} \mathrm{H}_{16} \mathrm{O}_{4}$

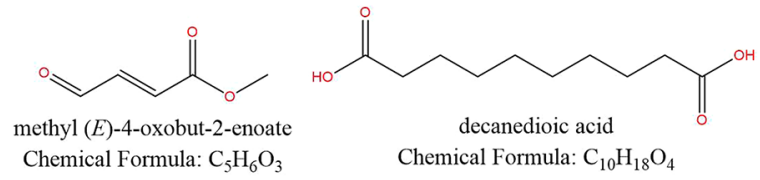

Figure 8. Main carboxylates and esters detected by HPLC-HRMS in the brine effluent. The formulas were assigned by the evaluation of the measured and predicted MS/MS spectra via mzLogic algorithm in the Compound Discoverer 3.1 software.

Table 5. Molar Flows of Positive and Negative Charges in and out of the Salt Separator during cHTG of Concentrated Pine Wood HTL Process Water

$\begin{array}{lc}\text { ions or class of ions } & \text { feed } \\ & \\ \mathrm{K}^{+} & 501 \pm 26 \\ \mathrm{Na}^{+} & 24 \pm 2 \\ \text { others }^{a} & 18 \pm 2 \\ \text { total } & 543 \pm 26 \\ \mathrm{CO}_{3}{ }^{2-} & <0.62 \\ \mathrm{~S}^{b} & <3.5 \\ \mathrm{Si}^{c} & 4.1 \pm 1.3 \\ \text { monocarboxylate }^{d} & \\ \text { dicarboxylate }^{d} & \\ \text { tricarboxylate }^{d} & \\ \text { total } & \end{array}$

$$
\begin{gathered}
\text { brine effluent } \\
\text { mmole }_{\text {charge }} \cdot \mathrm{h}^{-1} \\
\text { cations } \\
476 \pm 24 \\
23 \pm 2 \\
1 \pm 0.6 \\
499 \pm 25 \\
\text { anions } \\
48 \pm 3 \\
0.9 \pm 0.3 \\
0.20 \pm 0.06 \\
43 \pm 1 \\
216 \pm 14 \\
3.9 \pm 0.1 \\
314 \pm 19
\end{gathered}
$$

$$
\begin{gathered}
\text { desalinated effluent } \\
\text { mmole }_{\text {charge }} \cdot h^{-1} \\
16.8 \pm 0.9 \\
1.1 \pm 0.2 \\
0.12 \pm 0.02 \\
18 \pm 1 \\
0.9 \pm 0.6 \\
<0.1 \\
0.07 \pm 0.03
\end{gathered}
$$$$
\begin{aligned}
& \text { total effluents out } \\
& \text { mmole }_{\text {charge }} \cdot \mathrm{h}^{-1}
\end{aligned}
$$

$493 \pm 25$

$24 \pm 2$

$1.1 \pm 0.6$

$517 \pm 26$

$49 \pm 3$

$0.9 \pm 0.3$

$0.3 \pm 0.1$

$43 \pm 1$

$216 \pm 14$

$3.9 \pm 0.1$

$315 \pm 20$

${ }^{a}$ Mostly Ca, Mg, Fe, Mn, and Zn. ${ }^{b}$ Assuming two charges per sulfur (sulfates or sulfites). ${ }^{c}$ Assuming two charges per silicon (silicate). ${ }^{d}$ Assuming the identified raw formulas $\mathrm{C}_{x} \mathrm{H}_{y} \mathrm{O}_{3}, \mathrm{C}_{x} \mathrm{H}_{y} \mathrm{O}_{4}$, and $\mathrm{C}_{x} \mathrm{H}_{y} \mathrm{O}_{6}$ (cf. Figure 9) are all assigned to mono-, di-, and tricarboxylates, respectively (one, two, and three charges).

Such a significant separation of carboxylates in supercritical water is quite unexpected, taking into consideration that the formation of $\mathrm{CO}_{2},{ }^{12,49} \mathrm{H}_{2} \mathrm{~S}$, ${ }^{13,50}$ or $\mathrm{NH}_{3}{ }^{12,51}$ are quite favored in supercritical water, even at a $\mathrm{pH}$ strongly favoring the formation of salts.

\section{Optimization of Gasification Efficiency}

The high carboxylate concentration in the brine and the resulting loss of chemical energy encouraged us to find solutions to favor the decomposition of carboxylates into carbonates and noncharged organics that would leave the salt separator in the desalinated stream. Watanabe et al. studied the decomposition of acetic acid ${ }^{52}$ and stearic acid ${ }^{53}$ in supercritical water and the effect of additives. In both cases, they reported very low decomposition rates at $673 \mathrm{~K}$, a rate that increased 16-fold for stearic acid and $>50$-fold for acetic acid when using $1 \mathrm{~mole} \cdot \mathrm{L}^{-1}$ $\mathrm{KOH}$ solution. Competitive monomolecular and bimolecular decarboxylations were evidenced in the case of acetic acid (formation of acetone), while stearic acid (18-carbon chain) was found to decompose mainly to $\mathrm{C}_{16}$ alkenes and acetic acid. Note that the rate of conversion of the fatty acid has been reported to be influenced by water density. It was found to increase by a factor of 2.3 when the water density decreased from 0.31 to 0.15 $\mathrm{g} \cdot \mathrm{cm}^{-3}$ at $658 \mathrm{~K}$ but was not affected from 0.31 to $0.50 \mathrm{~g} \cdot \mathrm{cm}^{-3} \cdot{ }^{54}$

In order to identify the optimized process conditions, four experiments were performed in a batch reactor at temperatures 


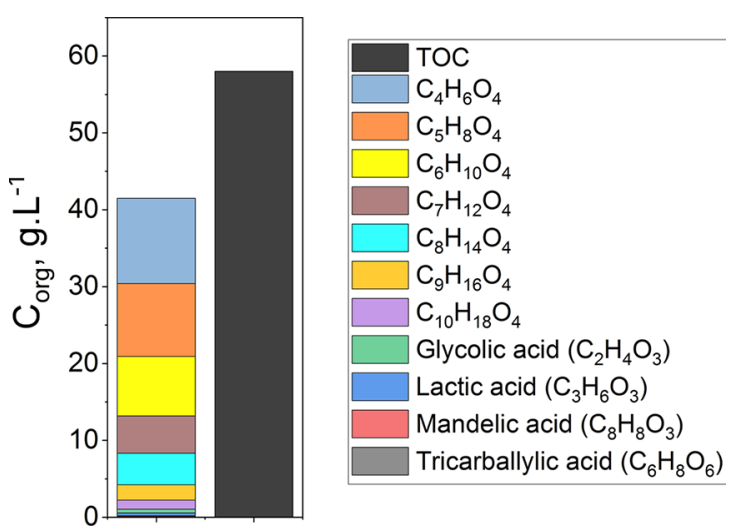

Figure 9. Cumulative semiquantitative carbon-based concentration of the main carboxylates identified by HPLC-HRMS compared to the total organic carbon in the brine.

between 673 and $768 \mathrm{~K}$ with the same but aged HTL process water used in the continuous test. The impact of the temperature on the concentration of carboxylates and carbonates was evaluated by HPLC-HRMS and TIC measurement, respectively.

As it can be seen in Table 6, carbonates were formed in significant quantities after hydrothermal treatment at $673 \mathrm{~K}$. The

Table 6. Decarboxylation Batch Experiments Performed on the HTL Process Water at Various Conditions at a Residence Time of $15 \mathrm{~min}$

\begin{tabular}{|c|c|c|c|c|c|}
\hline \multirow[t]{2}{*}{$\begin{array}{c}\text { run } \\
\text { number }\end{array}$} & \multirow{2}{*}{$\begin{array}{c}\begin{array}{c}\text { temperature/ } \\
\text { pressure }\end{array} \\
(\mathrm{K} / \mathrm{MPa})\end{array}$} & \multicolumn{2}{|c|}{ inorganic $\mathrm{C}$ yields $^{a}$} & \multirow{2}{*}{$\begin{array}{c}\text { carboxylate } \\
\text { concentration }^{c, d} \\
\left(\mathrm{mmole}_{\mathrm{COO}}-\cdot \mathrm{L}^{-1}\right)\end{array}$} & \multirow[t]{2}{*}{$\mathrm{pH}$} \\
\hline & & $\begin{array}{c}\mathrm{CO}_{3}^{2-} \\
(\mathrm{mol} \%)\end{array}$ & $\begin{array}{c}\mathrm{CO}_{x}^{b} \\
(\operatorname{mol} \%)\end{array}$ & & \\
\hline feed & & $0.002^{e}$ & & $23 \pm 3$ & 5.52 \\
\hline 1 & $673 / 26.0$ & $7 \pm 2$ & $16 \pm 2$ & $44 \pm 5$ & 8.86 \\
\hline 2 & $723 / 29.3$ & $8 \pm 2$ & $14 \pm 4$ & $14 \pm 2$ & 8.52 \\
\hline 3 & $723 / 30.8$ & $9 \pm 2$ & $14 \pm 4$ & $18 \pm 2$ & 8.73 \\
\hline 4 & $768 / 27.4$ & $20 \pm 3$ & $12 \pm 4$ & $0.9 \pm 0.1$ & 8.76 \\
\hline
\end{tabular}

${ }^{a}$ Molar yields based on the moles of carbon in the feed solution. ${ }^{b}$ Calculated from the sum of $\mathrm{CO}$ and $\mathrm{CO}_{2}$ in the gas phase, divided by the total carbon content in the feed. ${ }^{c}$ Cumulated semiquantitative carbon-based concentration of the main carboxylates identified by HPLC-HRMS. ${ }^{d}$ Standard deviation indicated corresponds to analytical deviation. ${ }^{e}$ Ratio between dissolved inorganic carbon and total carbon.

quantity of carbonates increased only slightly when the temperature rose from 673 to $723 \mathrm{~K}$, which was the highest temperature used in the salt separator during the continuous test. However, a 2.4-fold increase was observed when the temperature was increased further from 723 to $768 \mathrm{~K}$, reaching a yield of $20 \mathrm{~mol} \%$ from the carbon present in the feed. In parallel, the concentration of $\mathrm{CO}$ and $\mathrm{CO}_{2}$ in the gas phase decreased stepwise while increasing temperature, partially explained by an increase of the concentration of $\mathrm{H}_{2}$ and $\mathrm{CH}_{4}$ (see the Supporting Information). The relative yield of methane increased by a factor of 4 when increasing the temperature from 723 to $768 \mathrm{~K}$, but the $\mathrm{H}_{2}$ yield only increased by a factor of 1.4 , while a rise of temperature should lead to an increase of the $\mathrm{H}_{2} / \mathrm{CH}_{4}$ ratio. This can partially be explained by an increase in the decarboxylation rate, whose mechanism leads also to the formation of methane. ${ }^{53}$ The $\mathrm{pH}$ of the aqueous phase produced from the tests ranged from 8.5 to 8.8 , a significant increase with regards to the feed ( $\mathrm{pH}$ 5.5) and explains why most of the $\mathrm{CO}_{2}$ produced remains in the liquid phase as carbonates. This is inline with the high $\mathrm{pH}$ of the brine observed during the continuous experiments.

HPLC-HRMS was used to semiquantify the main carboxylates present in the solution to complement the inorganic carbon yields obtained. The overall concentration is given in Table 6. Note the dicarboxylates quantified in the feed only represent $1.9 \mathrm{~g}_{\mathrm{C}} \cdot \mathrm{L}^{-1}$ and $5 \%$ of the anionic charges, with the latter indicating the presence of a larger variety of carboxylates. The total concentration of carboxylates increased from 23

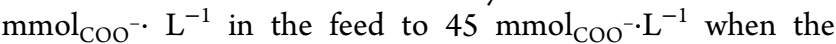
solution was heated to $673 \mathrm{~K}$ at $26 \mathrm{MPa}$. Details on the semiquantitative carbon-based concentration of the main carboxylates identified by HPLC-HRMS can be found in the Supporting Information. Interestingly, mainly $\mathrm{C}_{4} \mathrm{H}_{6} \mathrm{O}_{4}$ and $\mathrm{C}_{5} \mathrm{H}_{8} \mathrm{O}_{4}$ seem to have increased in concentration, which would be in phase with cracking of large organic compounds and possibly from the high share of unidentified carboxylates present in the feed. This increase of carboxylate concentration could have originated from the hydrolysis of esters present in the feed. However, data from HPLC-HRMS proved that esters were not present in a significant amount in the feed, excluding this possibility. The formation of carboxylic acids from lignocellulosic biomass under reductive hydrothermal conditions is well-known with the formation of simple compounds such as formic, acetic, or lactic acids reported ${ }^{55-57}$ but also more complex ones such as levulinic acid ${ }^{56,57}$ or homovanillic acid. ${ }^{58}$ The mechanism for the formation of larger carboxylates is not fully understood but is believed to involve benzilic acid rearrangement. ${ }^{56,59,60}$ Note also that carboxylates such as lactate are formed by the hydrothermal oxidation of organics with $\mathrm{CO}_{2}$, particularly under alkaline conditions. ${ }^{59,61}$

When heating to $723 \mathrm{~K}$, the carboxylate concentration

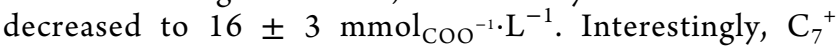
dicarboxylates were barely affected by this rise of temperature. Note that the experimental error is larger than the analytical standard deviation indicated, which might be a result of small variation in the fluid density resulting from small differences in temperature, pressure, and gas concentration. ${ }^{54}$ When heating the solution at $768 \mathrm{~K}$, almost no carboxylates were left in the

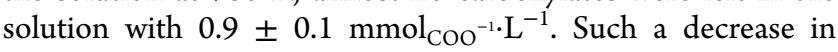
carboxylate concentration indicates that increasing the temperature in the salt separation unit to ca. $768 \mathrm{~K}$ can optimize the overall gasification efficiency during continuous cHTG of lignocellulosic-based process waters (e.g., Miscanthus, wood).

\section{CONCLUSION}

The valorization of a process water produced from the $\mathrm{KOH}$ catalyzed HTL of pine wood by CHTG was evaluated. The salt separator developed at PSI allowed for a smooth and continuous extraction of salts by up to $98 \%$. However, the gasification efficiency is reduced by the high concentration of mono-, di-, and tricarboxylates separated and concentrated in the brine, as evidenced by HPLC-HRMS semiquantitative analysis. The operation of the salt separator at temperatures close to or greater than $768 \mathrm{~K}$ is suggested in order to reach a low concentration of carboxylates and allows for the highest SNG production in cHTG process. As importantly, the bottom of the salt separator where the brine outlet is located should be maintained as hot as possible but below the critical point to allow for the redissolution of solid salts. 
Some biomass or waste streams such as HTL process water contain a high amount of volatile organic compounds that can significantly impact the determination of the HHV of an aqueous solution. HHV measured on DM can be compared to a HHV calculated from the total carbon of the fresh solution. If the difference is significant, the HHV can be more accurately calculated from the COD measurement of the aqueous solution using an equation based on the correlation between COD and HHV.

\section{ASSOCIATED CONTENT}

\section{Supporting Information}

The Supporting Information is available free of charge at https://pubs.acs.org/doi/10.1021/acsengineeringau.1c00010.

Figures of evolution of the pressure and temperature, evolution of average temperature, correlation between COD and HHV, Kroll diagrams, volcano plots, Van Krevelen plot, MW vs DBE, and heteroatom class distributions, pressure and temperature profiles, and semiquantitative carbon-based concentration of the main dicarboxylates identifed by HPLC-HRMS and tables of mass, energy, and molar flows and gas composition and yield from the batch tests (PDF)

\section{AUTHOR INFORMATION}

\section{Corresponding Author}

David Baudouin - Laboratory for Bioenergy and Catalysis, Paul Scherrer Institute (PSI), 5232 Villigen PSI, Switzerland; (1) orcid.org/0000-0002-8428-990X; Phone: +41 5631056 94; Email: david.baudouin@psi.ch

\section{Authors}

Daniil Salionov - Laboratory for Bioenergy and Catalysis, Paul Scherrer Institute (PSI), 5232 Villigen PSI, Switzerland

Frédéric Vogel - Laboratory for Bioenergy and Catalysis, Paul Scherrer Institute (PSI), 5232 Villigen PSI, Switzerland; Institute for Biomass and Resource Efficiency, University of Applied Sciences Northwestern Switzerland (FHNW), 5210

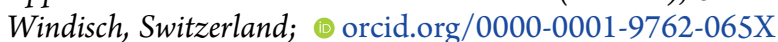

Saša Bjelić - Laboratory for Bioenergy and Catalysis, Paul Scherrer Institute (PSI), 5232 Villigen PSI, Switzerland; (1) orcid.org/0000-0002-9805-3201

Complete contact information is available at: https://pubs.acs.org/10.1021/acsengineeringau.1c00010

Notes

The authors declare no competing financial interest.

\section{ACKNOWLEDGMENTS}

Funding: This research was funded by the European Union's Horizon 2020 research and innovation programme under grant agreement No. 764734 (HyFlexFuel - Hydrothermal liquefaction: Enhanced performance and feedstock flexibility for efficient biofuel production) and by the Swiss Competence Center for Energy Research SCCER BIOSWEET of the Swiss Innovation Agency Innosuisse. Financial support is graciously acknowledged from the ETH domain (Switzerland) via the funds for "Coordinated Research", which allowed for setting up the Energy System Integration (ESI) Platform at PSI hosting the continuous CHTG unit KONTI-C. The authors acknowledge G. Becker and E. Ovsyannikova from Hohenheim University for their constructive discussion and support with ICP-OES analysis, K. Anastasakis, M. Glasius, and P. Biller from Aarhus University for supplying HTL process water, and E. De Boni, P. Unverricht, Y. Bäuerle, L. Koning, M. Szostak, C. Hunston, T. Käser, and K. Arturi from PSI for technical and experimental help.

\section{REFERENCES}

(1) de Jong, S.; Hoefnagels, R.; Faaij, A.; Slade, R.; Mawhood, R.; Junginger, $M$. The feasibility of short-term production strategies for renewable jet fuels - a comprehensive techno-economic comparison. Biofuels, Bioprod. Biorefin. 2015, 9, 778-800.

(2) Anastasakis, K.; Biller, P.; Madsen, R.; Glasius, M.; Johannsen, I. Continuous Hydrothermal Liquefaction of Biomass in a Novel Pilot Plant with Heat Recovery and Hydraulic Oscillation. Energies 2018, 11, 2695.

(3) HyFlexFuel-Hydrothermal liquefaction: Enhanced performance and feedstock flexibility for efficient biofuel production. https://www. hyflexfuel.eu/ (accessed on 2021-01-06).

(4) Haider, M. S.; Castello, D.; Rosendahl, L. A. Two-stage catalytic hydrotreatment of highly nitrogenous biocrude from continuous hydrothermal liquefaction: A rational design of the stabilization stage. Biomass Bioenergy 2020, 139, 105658.

(5) Ovsyannikova, E.; Kruse, A.; Becker, G. C. Feedstock-Dependent Phosphate Recovery in a Pilot-Scale Hydrothermal Liquefaction BioCrude Production. Energies 2020, 13, 379.

(6) Arlene Karidis, U. District Pilot to Transform Organic Waste into Liquid Transportation Fuels. https://www.waste360.com/fuel/districtpilot-transform-organic-waste-liquid-transportation-fuels (accessed on 2021-01-06).

(7) Zöhrer, H.; Mayr, F.; Vogel, F. Stability and Performance of Ruthenium Catalysts Based on Refractory Oxide Supports in Supercritical Water Conditions. Energy Fuels 2013, 27, 4739-4747.

(8) Elliott, D. C.; Hart, T. R.; Schmidt, A. J.; Neuenschwander, G. G.; Rotness, L. J.; Olarte, M. V.; Zacher, A. H.; Albrecht, K. O.; Hallen, R. T.; Holladay, J. E. Process development for hydrothermal liquefaction of algae feedstocks in a continuous-flow reactor. Algal Res. 2013, 2, $445-454$.

(9) Kruse, A.; Forchheim, D.; Gloede, M.; Ottinger, F.; Zimmermann, $\mathrm{J}$. Brines in supercritical biomass gasification: 1 . Salt extraction by salts and the influence on glucose conversion. J. Supercrit. Fluids 2010, 53, 64-71.

(10) Marrone, P. A.; Hodes, M.; Smith, K. A.; Tester, J. W. Salt precipitation and scale control in supercritical water oxidation-part B: commercial/full-scale applications. J. Supercrit. Fluids 2004, 29, 289312.

(11) Reimer, J.; Peng, G.; Viereck, S.; De Boni, E.; Breinl, J.; Vogel, F. A novel salt separator for the supercritical water gasification of biomass. J. Supercrit. Fluids 2016, 117, 113-121.

(12) Schubert, M.; Regler, J. W.; Vogel, F. Continuous salt precipitation and separation from supercritical water. Part 1: Type 1 salts. J. Supercrit. Fluids 2010, 52, 99-112.

(13) Wang, R.; Deplazes, R.; Vogel, F.; Baudouin, D. Continuous Extraction of Black Liquor Salts under Hydrothermal Conditions. Ind. Eng. Chem. Res. 2021, 60, 4072-4085.

(14) Valyashko, V. M. Hydrothermal Experimental Data; John Wiley \& Sons, Ltd., 2008; pp 1-133.

(15) Schubert, M.; Regler, J. W.; Vogel, F. Continuous salt precipitation and separation from supercritical water. Part 2. Type 2 salts and mixtures of two salts. J. Supercrit. Fluids 2010, 52, 113-124.

(16) Schubert, M.; Aubert, J.; Müller, J. B.; Vogel, F. Continuous Salt Precipitation and Separation from Supercritical Water. Part 3: Interesting Effects in Processing Type 2 Salt Mixtures. J. Supercrit. Fluids 2012, 61, 44.

(17) Peng, G. Methane Production from Microalgae via Continuous Catalytic Supercritical Water Gasification: Development of Catalysts and Sulfur Removal Techniques. PhD thesis, EPFL, Lausanne, Switzerland, 2015. 
(18) Vogel, F. Handbook of Green Chemistry; Anastas, P. T., Ed.; Wiley-VCH Verlag GmbH and Co. KGaA, 2010; pp 281-324.

(19) Hunston, C.; Baudouin, D.; Tarik, M.; Kröcher, O.; Vogel, F. Investigating Active Phase Loss from Supported Ruthenium Catalysts during Supercritical Water Gasification. Catal. Sci. Technol. 2021, DOI: $10.1039 / \mathrm{D} 1 \mathrm{CY} 00379 \mathrm{H}$.

(20) Peng, G.; Vogel, F.; Refardt, D.; Ludwig, C. Catalytic Supercritical Water Gasification: Continuous Methanization of Chlorella vulgaris. Ind. Eng. Chem. Res. 2017, 56, 6256-6265.

(21) Baudouin, D.; Vogel, F. Catalytic hydrothermal gasification campaigns with various feedstocks. Unpublished, 2018-2020.

(22) Usman, M.; Chen, H.; Chen, K.; Ren, S.; Clark, J. H.; Fan, J.; Luo, G.; Zhang, S. Characterization and utilization of aqueous products from hydrothermal conversion of biomass for bio-oil and hydro-char production: a review. Green Chem. 2019, 21, 1553-1572.

(23) Zhang, B.; Chen, H.; He, Z. Catalytic hydrothermal liquefaction of Spirulina platensis: Focusing on aqueous phase characterization. Int. J. Energy Res. 2019, 43, 7135-7145.

(24) Panisko, E.; Wietsma, T.; Lemmon, T.; Albrecht, K.; Howe, D. Characterization of the aqueous fractions from hydrotreatment and hydrothermal liquefaction of lignocellulosic feedstocks. Biomass Bioenergy 2015, 74, 162-171.

(25) Gai, C.; Zhang, Y.; Chen, W.-T.; Zhou, Y.; Schideman, L.; Zhang, P.; Tommaso, G.; Kuo, C.-T.; Dong, Y. Characterization of aqueous phase from the hydrothermal liquefaction of Chlorella pyrenoidosa. Bioresour. Technol. 2015, 184, 328-335.

(26) Maddi, B.; Panisko, E.; Wietsma, T.; Lemmon, T.; Swita, M.; Albrecht, K.; Howe, D. Quantitative characterization of the aqueous fraction from hydrothermal liquefaction of algae. Biomass Bioenergy 2016, 93, 122-130.

(27) Bjelic, S.; Yu, J.; Iversen, B. B.; Glasius, M.; Biller, P. Detailed investigation into the asphaltene fraction of hydrothermal liquefaction derived bio-crude and hydrotreated bio-crudes. Energy Fuels 2018, 32, 3579-3587.

(28) Zöhrer, H.; Vogel, F. Hydrothermal catalytic gasification of fermentation residues from a biogas plant. Biomass Bioenergy 2013, 53, $138-148$.

(29) NIST Standard Reference Database Number 69. NIST Chemistry WebBook. http://webbook.nist.gov/chemistry/ (accessed on 2020-09$01)$.

(30) HighChem Ltd. mzCloud - Advanced Mass Spectral Database. https://www.mzcloud.org/ (accessed on 2018-02-25).

(31) Royal Society of Chemistry. ChemSpider. http://www. chemspider.com/ (accessed on 2018-02-25).

(32) van Krevelen, D. W. Graphical statistical method for the study of structure and reaction processes of coal. Fuel 1950, 29, 269-284.

(33) Koch, B. P.; Dittmar, T. From mass to structure: An aromaticity index for high-resolution mass data of natural organic matter. Rapid Commun. Mass Spectrom. 2006, 20 (5), 926-932.

(34) Cui, X.; Churchill, G. A. Statistical tests for differential expression in cDNA microarray experiments. Genome Biol. 2003, 4, 210.

(35) McKinney, W.; van der Walt, S.; Millman, J. Data structures for statistical computing in Python. Proceedings of the 9th Python in Science Conference, Austin, TX, June 18-July 3, 2010; pp 51-56.

(36) Scott, D. W. Multivariate density estimation: theory, practice, and visualization; John Wiley \& Sons, 2015.

(37) Hunter, J. D. Matplotlib: A 2D graphics environment. Comput. Sci. Eng. 2007, 9, 90-95.

(38) Oss, M.; Kruve, A.; Herodes, K.; Leito, I. Electrospray ionization efficiency scale of organic compounds. Anal. Chem. 2010, 82, 28652872.

(39) Kruse, A. Supercritical Water Gasification. Biofuels, Bioprod. Biorefin. 2008, 2, 415.

(40) Hita, I.; Deuss, P.; Bonura, G.; Frusteri, F.; Heeres, H. Biobased chemicals from the catalytic depolymerization of Kraft lignin using supported noble metal-based catalysts. Fuel Process. Technol. 2018, 179, $143-153$.

(41) Zoppi, G.; Pipitone, G.; Galletti, C.; Rizzo, A. M.; Chiaramonti, D.; Pirone, R.; Bensaid, S. Aqueous phase reforming of lignin-rich hydrothermal liquefaction by-products: A study on catalyst deactivation. Catal. Today 2021, 365, 206-213.

(42) Reimer, J.; Vogel, F. High pressure differential scanning calorimetry of the hydrothermal salt solutions $\mathrm{K}_{2} \mathrm{SO}_{4}-\mathrm{Na}_{2} \mathrm{SO}_{4}-\mathrm{H}_{2} \mathrm{O}$ and $\mathrm{K}_{2} \mathrm{HPO}_{4}-\mathrm{H}_{2} \mathrm{O}$. RSC Adv. 2013, 3, 24503-24508.

(43) Voisin, T.; Erriguible, A.; Ballenghien, D.; Mateos, D.; Kunegel, A.; Cansell, F.; Aymonier, C. Solubility of inorganic salts in sub- and supercritical hydrothermal environment: Application to SCWO processes. J. Supercrit. Fluids 2017, 120, 18-31.

(44) Schubert, M.; Müller, J. B.; Vogel, F. Continuous hydrothermal gasification of glycerol mixtures: Effect of glycerol and its degradation products on the continuous salt separation and the enhancing effect of K3PO4 on the glycerol degradation. J. Supercrit. Fluids 2014, 95, 364372.

(45) Channiwala, S. A.; Parikh, P. P. A unified correlation for estimating HHV of solid, liquid and gaseous fuels. Fuel 2002, 81, 10511063.

(46) Friedl, A.; Padouvas, E.; Rotter, H.; Varmuza, K. Prediction of heating values of biomass fuel from elemental composition. Anal. Chim. Acta 2005, 544, 191-198.

(47) Wilson, D. L. Prediction of heat of combustion of solid wastes from ultimate analysis. Environ. Sci. Technol. 1972, 6, 1119-1121.

(48) Tillman, D. A. Wood as an energy resource; Elsevier: New York, 1978.

(49) Khan, M. S.; Rogak, S. N. Solubility of $\mathrm{Na}_{2} \mathrm{SO}_{4}, \mathrm{Na}_{2} \mathrm{CO}_{3}$ and their mixture in supercritical water. J. Supercrit. Fluids 2004, 30, 359-373.

(50) Yakaboylu, O.; Harinck, J.; Gerton Smit, K. G.; de Jong, W. Supercritical water gasification of manure: A thermodynamic equilibrium modeling approach. Biomass Bioenergy 2013, 59, 253-263.

(51) Schoppelrei, J. W.; Kieke, M. L.; Brill, T. B. Spectroscopy of Hydrothermal Reactions. 2. Reactions and Kinetic Parameters of $[\mathrm{NH} 3 \mathrm{OH}] \mathrm{NO} 3$ and Equilibria of $(\mathrm{NH} 4) 2 \mathrm{CO} 3$ Determined with a Flow Cell and FT Raman Spectroscopy. J. Phys. Chem. 1996, 100, 7463-7470.

(52) Watanabe, M.; Inomata, H.; Smith, R. L.; Arai, K. Catalytic decarboxylation of acetic acid with zirconia catalyst in supercritical water. Appl. Catal., A 2001, 219, 149-156.

(53) Watanabe, M.; Iida, T.; Inomata, H. Decomposition of a long chain saturated fatty acid with some additives in hot compressed water. Energy Convers. Manage. 2006, 47, 3344-3350.

(54) Fu, J.; Shi, F.; Thompson, L. T.; Lu, X.; Savage, P. E. Activated Carbons for Hydrothermal Decarboxylation of Fatty Acids. ACS Catal. 2011, 1, 227-231.

(55) Kabyemela, B. M.; Adschiri, T.; Malaluan, R. M.; Arai, K. Glucose and Fructose Decomposition in Subcritical and Supercritical Water: Detailed Reaction Pathway, Mechanisms, and Kinetics. Ind. Eng. Chem. Res. 1999, 38, 2888-2895.

(56) Aida, T. M.; Tajima, K.; Watanabe, M.; Saito, Y.; Kuroda, K.; Nonaka, T.; Hattori, H.; Smith, R. L.; Arai, K. Reactions of d-fructose in water at temperatures up to $400^{\circ} \mathrm{C}$ and pressures up to $100 \mathrm{MPa}$. $J$. Supercrit. Fluids 2007, 42, 110-119.

(57) Antal, M. J.; Mok, W. S. L.; Richards, G. N. Mechanism of formation of 5-(hydroxymethyl)-2-furaldehyde from d-fructose and sucrose. Carbohydr. Res. 1990, 199, 91-109.

(58) Abad-Fernández, N.; Pérez, E.; Martín, A.; Cocero, M. J. Kraft lignin depolymerisation in sub- and supercritical water using ultrafast continuous reactors. Optimization and reaction kinetics. J. Supercrit. Fluids 2020, 165, 104940.

(59) Shen, Z.; Gu, M.; Zhang, M.; Sang, W.; Zhou, X.; Zhang, Y.; Jin, $\mathrm{F}$. The mechanism for production of abiogenic formate from $\mathrm{CO}_{2}$ and lactate from glycerine: uncatalyzed transfer hydrogenation of $\mathrm{CO}_{2}$ with glycerine under alkaline hydrothermal conditions. RSC $A d v$. 2014, 4, $15256-15263$.

(60) Wang, Y.; Wang, F.; Li, C.; Jin, F. Kinetics and mechanism of reduction of $\mathrm{CO}_{2}$ by glycerol under alkaline hydrothermal conditions. Int. J. Hydrogen Energy 2016, 41, 9128-9134.

(61) Andérez-Fernández, M.; Pérez, E.; Martín, A.; Bermejo, M. D. Hydrothermal $\mathrm{CO} 2$ reduction using biomass derivatives as reductants. J. Supercrit. Fluids 2018, 133, 658-664. 